\title{
DISCIPLINA DEL CONTRATO, TUTELA DEL CONTRATANTE MÁS DÉBIL Y VALOR CONSTITUCIONAL ${ }^{1}$
}

\author{
Contract Discipline, Protection of the Weaker Party and \\ Contitutional Value
}

\section{LORENZO MEZZASOMA \\ Catedrático de Derecho Civil \\ Universidad de Perugia}

\author{
Recepción: 20/06/2015 \\ Aceptación después de revisión: 17/07/2015 \\ Publicación: 27/11/2015
}

I. EVOLUCIÓN DEL CONTRATO Y NUEVA NECESIDAD DE TUTELA. II. EL FUNDAMENTO CONSTITUCIONAL DE LA TUTELA DEL CONTRATANTE MÁS DÉBIL. III. LA FORMA DEL CONTRATO EN EL CÓDIGO CIVIL Y EN LAS NORMAS DEL SECTOR: EL NEOFORMALISMO. IV. LA FORMA EN EL CONTRATO DE VENTA DE PAQUETES TURÍSTICOS. V. LA NULIDAD DEL CONTRATO EN EL CÓDIGO CIVIL Y EN LAS NORMAS DEL SECTOR: LA NULIDAD DE PROTECCIÓN. VI. CONCLUSIONES.

\section{RESUMEN}

El artículo examina la incidencia de los principios constitucionales en el derecho de contratos con el fin de subrayar cómo los clásicos institutos negociales han visto cambiar su función y su disciplina. Se analizan, en particular, las cuestiones relacionadas con la forma de los contratos y con la sanción de la nulidad.

PALABRAS CLAVE: Principios constitucionales; autonomía negocial; forma; nulidad.

\section{ABSTRACT}

The paper examines the incidence of constitutional principles in the law of contracts in order to highlight how the classic negotiating institutions have seen change their function and their discipline. Are analyzed, in particular, issues related to the form of contracts and nullity.

${ }^{1}$ La traducción del presente trabajo ha sido realizada por el Prof. Eduardo Vázquez de Castro. 
KEY WORDS: Constitutional principles; negocial autonomy; form of contracts; nullity.

\section{EVOLUCIÓN DEL CONTRATO Y NUEVA NECESIDAD DE TUTELA}

Los cambios radicales que, progresivamente, se han experimentado en el ámbito económico, han traído consigo la necesidad de adaptar los contratos en términos muy diversos a los utilizados en el pasado. El contrato, en efecto, aparece como el instrumento jurídico principal mediante el cual se expresa la economía moderna y, todo ello, supone un necesario paralelismo evolutivo entre modificaciones estructurales del mercado y cambios normativos en materia contractual $^{2}$.

${ }^{2}$ G. VetTori (a cura di), Materiali e commenti sul nuovo diritto dei contratti, Padova, 1999; P. PERLINGIERI, Nuovi profili del contratto, en Rass. dir. civ., 2000, pp. 545 y ss., y en ID., Il diritto dei contratti fra persona e mercato. Problemi di diritto civile, Napoli, 2003, pp. 417 y ss.; A. GENTILI, I principi del diritto contrattuale europeo: verso una nuova nozione di contratto?, en Riv. dir. priv., 2001, pp. 20 y ss.; V. Roppo, Contratto di diritto comune, contratto del consumatore, contratto con asimmetria di potere contrattuale: genesi e sviluppi di un nuovo paradigma, en Il contratto del duemila, Torino, 2002, pp. 23 y ss.; ID., Parte generale del contratto, contratti del consumatore e contratti asimmetrici (con postilla sul «terzo contratto»), en Riv. dir. priv., 2007, pp. 669 y ss.; P.G. MonATERI, Ripensare il contratto: verso una visione antagonista del contratto, en Riv. dir. civ., 2003, I, pp. 409 y ss.; V. RIzzo, Recenti itinerari del contratto e vessatorietà, en Temi e problemi della civilistica contemporanea, Quaderni Rass dir. civ., Napoli, 2005, pp. 37 y ss.; F. CRISCUOLO, Diritto dei contratti e sensibilità dell'interprete, Napoli, 2003, pp. 168 y ss.; G.P. CALABRò, Tutela del contraente debole e mercato: la dialettica tra norme e valori, en P. PERLINGIERI y E. CATERINI (a cura di), Il diritto dei consumi, Napoli, 2005, I, pp. 35 y ss.; M. Pennasilico, L'interpretazione dei contratti del consumatore, ivi, pp. 148 y ss.; F. GALGANO, Lex mercatoria, autonomia privata e disciplina del mercato, en M. PARADISO (a cura di), I mobili confini dell'autonomia privata, Milano, 2005, pp. 680 y ss.; ID., Prefazione, en V. Ricciuto y N. Zorzi (a cura di), Il contratto telematico, Tratt. dir. comm. dir. pubbl. ec. dirigido por F. Galgano, XXVII, Padova, 2002, p. XV; N. LIPARI, Interpretazione e integrazione del regolamento contrattuale, en Atti del Convegno «Il diritto delle obbligazioni e dei contratti: verso una riforma?», Treviso 23-25 marzo 2006, en Riv. dir. civ., 2006, p. 235; M FRANZONI, Il contratto nel mercato globale, en Jus Civile, 2013, pp. 13 y ss. Por ultimo, V. Ricciuto, Le pratiche commerciali scorrette nella contrattazione a distanza, en Riv. dir. impr., 2015, pp. 1 y ss. 
En las relaciones económicas, sobre todo si son enfocadas a acuerdos negociados para la distribución al público de bienes o servicios, resalta, con gran incidencia, los desequilibrios en las negociaciones, manifestados en la falta de acuerdo de los contratantes, que poseen conocimientos, capacidad y fuerza negocial completamente diferente. A un «ingenioso» profesional, se contrapone - normalmente - un «ingenuo» consumidor que, de acuerdo con sus específicas características ${ }^{3}$, necesita una normativa favorable que se distancia de la contenida en el Código Civil italiano ya que esta, evidentemente, no resulta la más apropiada para ordenar correctamente el moderno tráfico económico ${ }^{4}$.

Una diferente fuerza negocial que, indudablemente, ha propiciado el surgimiento de una nueva problemática que, si de un lado ha determinado una fuerte revisión de las instituciones civilistas relativas al contrato ${ }^{5}$, del otro ha impulsado la necesidad de una reconsideración del propio concepto de autonomía privada ${ }^{6}$. Esta, en efecto, no podrá ser considerada como instrumento mediante el cual dar plena e integral fuerza vinculante a los contratantes. Sin embargo, se convierte en instrumento axiológicamente valorable que encontrará fuerza jurídica solo sobre la realización de intereses que sean merecedores de tutela constitucional ${ }^{7}$. Tal control sobre el

${ }^{3}$ L. Mezzasoma, Il consumatore e il professionista, en G. Recinto, L. MeZzasoMA y S. CHERTI (a cura di), Diritti e tutele dei consumatori, Napoli, 2014, pp. 13 y ss.

${ }^{4}$ G. Alpa, Artículo 1, en G. AlPa y L. Rossi Carleo (a cura di), Codice del consumo. Commentario, Napoli, 2005, p. 26; R. CALVo, I contratti del consumatore, en Tratt. dir. comm. dir. pubbl. ec. dirigido por F. Galgano, Padova, 2005, p. 2; L MezzAsoma, Novitá del diritto contrattuale in Italia e tutela del contraente debole, en Le Corti Umbre, 2014, pp. 919 y ss; V. Rizzo, Relazione introduttiva, ponencia al congreso «La riforma del codice del consumo nel prisma delle fonti», Bari, 15-16 de octubre de 2015

5 Vid. infra.

${ }^{6}$ R. DI RAIMO, Autonomia privata e dinamiche del consenso, Napoli, 2003, pp. 141 y ss., el cual se centra sobre varios instrumentos que han sido utilizados habitualmente para facilitar una adecuada tutela al contratante más débil. Vid., tambien, E. VÁzQUEZ DE CASTRO, Determinación del contenido del contrato: presupuestos y límites de la libertad contractual, Valencia, 2002, pp. 22 y ss.

${ }^{7}$ P. PERLINGIERI, Il diritto civile nella legalità costituzionale secondo il sistema italo-comunitario delle fonti, 3. ${ }^{\text {a }}$ ed., Napoli, 2006, pp. 321 y ss., criticando las recurrentes reconstrucciones de la autonomía negocial como institución fundada sobre la voluntad de las partes, afirma: «Estas construcciones se fundamentan íntegramente sobre el dogma de la autonomía privada que, sin embargo, no puede ser asumido como postulado. Debe preguntarse, en cambio, cuáles serían los aspectos sobre los que se manifiesta la autonomía negocial. Tradicionalmente, se responde que esta se traduce, en primer lugar, en la libertad de negociación, de elegir al contratante, de determinar el contenido del contrato o, en otro sentido, de elegir, en algunos casos, la forma del acto en cuestión. Es necesario verificar si tal libertad se encuentra efectivamente reflejada 
merecimiento de tutela ${ }^{8}$, aparentemente previsto sólo en relación a las figuras negociales atípicas por una superada interpretación del artículo 1.322, 2 $\mathrm{CC}$, es hoy necesario para cualquier manifestación de autonomía negocial, no pudiendo admitir que un acto que tenga fuerza de ley entre las partes pueda ser instrumento mediante el cual realizar intereses que choquen con los valores de nuestro ordenamiento. Esto implicó, sin embargo, la necesidad de no volver a ver en la autonomía negocial un instrumento compuesto, exclusivamente, de intereses patrimoniales, pero, por el contrario, la emersión de los valores y principios no patrimoniales también como tema central del derecho civil, han propiciado poder afirmar que todos los procesos económicos deben, necesariamente, ser considerados a la luz de la jerarquía de los valores que dominan nuestro ordenamiento y entre los cuales resalta, en particular, aquellos sobre la plena tutela de la persona ${ }^{9}$.

La proliferación de normas sectoriales que han incidido sobre la propia noción de autonomía negocial y, como se verá a continuación, sobre algunas de las instituciones clásicas del derecho de contratos, no se presenta absolutamente exenta de tal caracterización. Las disposiciones relativas a la tutela de los contratantes más débiles ${ }^{10}$, en efecto,

en la teoría de los actos, por la fisionomía que esta asume sobre la base de los principios generales del ordenamiento. Es de tales principios de los que se concluye la valoración de transparencia y abusividad de la autonomía negocial: esta, por tanto, no tiene un valor per se. Indispensablemente se presenta necesario la revisión de la noción a la luz del juicio de abusividad de las singulares decisiones para deducir si estos, individualmente considerados, pueden ser regulados, al menos en parte, por la autonomía negocial».

${ }^{8}$ Sobre el tema, G. BERTI DE MARINIS, El control sobre el merecimiento de tutela de la causa de los contratos, en Actualidad juridica iberoamericana, 2014, I, pp. 113 y ss.

${ }^{9}$ Cfr. P. PerlingIeri, Le insidie del nichilismo giuridico. Le ragioni del mercato e le ragioni del diritto, en ID., L'ordinamento vigente e $i$ suoi valori, Napoli, 2006, p. 233 (ya en Rass. dir. civ., 2005, pp. 1 y ss.): «La realidad no es reconducible a los aspectos económicos. Las razones del mercado son expresiones de una realidad más compleja, caracterizada también por los impulsos de diversa naturaleza inspirándose en las razones que son, no solo mercantiles, sino también éticas y/o religiosas, humanas y solidarias y que se proponen incluso como respuesta a las meras razones de mercado».

${ }^{10}$ En general, sobre este punto, G. VillanacCI (a cura di), Manuale di diritto dei consumi, Napoli, 2007, p. 12; E. Minervini, Codice del consumo, en Dig. disc. priv., Sez. civ., Agg., III, 1, 2007, pp. 183 y s.; G. VILlanacCI, Il diritto dei consumi e le istanze di tutela del contraente debole nel codice del consumo en el T.U.I.F., en ID. (a cura di), Consumo e consumismo fenomeno sociale e istanze di tutela, Napoli, 2009, pp. 81 y ss.; G. AlPa, G. Conte y L. Rossi Carleo, La costruzione del diritto dei consumi, en G. AlPa (a cura di), I diritti dei consumatori, I, en Tratt. dir. priv. Un. eur., III, dirigido por G. Ajani y G.A. Benacchio, Torino, 2009, pp. 2 y ss.; G. AlPA, Il 
además de encontrar plena justificación en aquellas normas destinadas a regular las relaciones económicas entre un profesional y un consumidor, encuentran también su valorada justificación en la exigencia de tutelar la persona-consumidor frente a todas aquellas actividades desarrolladas por el profesional que pueden vulnerar situaciones jurídicas constitucionalmente relevantes ${ }^{11}$.

Se afirmaría, por otra parte, una verdad solo parcial en el caso de que tratase de evidenciar como todas estas consideraciones, en el pasado limitadas a la contratación entre profesionales y consumidores y que encontraban en este su ámbito de aplicación, expanden su validez también a aquellas contrataciones entre profesionales que resultan caracterizados por los mismos desequilibrios que presentan las contrataciones realizadas con consumidores ${ }^{12}$.

Precisamente el surgimiento de esta nueva problemática también en la contratación entre empresas, ha provocado que parte de la doctrina acuñe, incluso, la definición de «tercer contrato» que, en contraposición al «primer» contrato regulado en el código civil y al «segundo» contrato regulado en las normas de protección al consumidor, reagruparía una disciplina específica para las contrataciones en desequilibrio entre profesionales ${ }^{13}$.

diritto dei consumi: un laboratorio per i giuristi, en G. AlPA, G. CONTE, V. DI GREGOrio, A. Fusaro y U. Perfetti (a cura di), Il diritto dei consumi. Aspetti e problemi, Napoli, 2010, pp. 11 y ss.; L. MezZASOMA, La protecciónón del consumidor y del usuario en el ordenamiento italiano (la noción de consumidor y usuario), en Revista Práctica Derecho de daños, La Ley, n. ${ }^{\circ} 116 / 2013$, pp. 8 y ss.

${ }^{11}$ L. Mezzasoma, Consumatore e costituzione, en Rass. dir. civ., 2015, pp. 313 y ss.; ID., Consumidor y Constitución, en AA.Vv., Homenaje al Prof. Guillelmo Figallo Adrianzén, Lima, en prensa.

${ }^{12}$ G. AmAdio, Nullità anomale e conformazione del contratto (note minime in tema di «abuso dell'autonomia contrattuale»), en Riv. dir. priv., 2005, pp. 289 y ss., por el cual «la identificación del contratante más débil en exclusiva relación con la dimensión (y legislación) de consumo es definitivamente superada, y junto a ella ha tenido éxito la imagen del profesional más débil, como protagonista de una tercera modalidad de contratación, para diferenciarla de las primeras dos: en esta, la asimetría del poder contractual adquiere connotaciones particulares, que requiere con toda probabilidad, un enfoque de protección diferenciado».

${ }^{13}$ R. PARdolesi, Prefazione, en G. Colangelo, L'abuso di dipendenza economica tra disciplina della concorrenza e diritto dei contratti. Un'analisi economica e comparata, Torino, 2004, pp. XII y ss.; G. GiTTI, Prefazione, en ID. (a cura di), Autonomia privata e le autorità indipendenti. Metamorfosi del contratto, Bologna, 2006, p. 12; A. Gianola, Autonomia privata e «terzo contratto», en P. RESCIGNO (a cura di), Autonomia privata individuale e collettiva, Napoli, 2006, pp. 131 y ss.; V. RopPo, Parte generale del contratto, contratti del consumatore e contratti asimmetrici (con postilla sul «terzo contratto»), en Riv. dir. priv., 2007, p. 697; G. GITTI y G. VILLA, Introduzione, en IDD. (a 
Como respuesta a la específica problemática derivada de tales perfiles, aparece evidente la necesidad de encuadrar la evolución de las concretas instituciones del contrato en el seno del contexto general. Sus motivos derivan, de un lado, de las profundas modificaciones económicas y de, igualmente, la incesante intervención normativa fruto del intento por afrontar las nuevas exigencia de la realidad social y, del otro lado, de los valores constitucionales actualmente establecidos que justifican la aplicación y condicionan su interpretación.

\section{EL FUNDAMENTO CONSTITUCIONAL DE LA TUTELA DEL CONTRATANTE MÁS DÉBIL}

Esta particular eficacia de los valores constitucionales en el seno de la disciplina legal de los contratos es evidente, particularmente, en la normativa sectorial sobre la tutela de los consumidores que encuentra su referencia en el c.d. del código de consumo (d.lg. 6 septiembre 2005, n. 206 - en adelante c. cons.-). Es precisamente en el seno de este texto normativo - continuamente objeto de reforma y actualización ${ }^{14}-$,

cura di), Il terzo contratto, Bologna, 2008, p. 7; E. NAVARRETTA, Luci ed ombre nell'immagine del terzo contratto, en G. GITTI y G. VILLA (a cura di), Il terzo contratto, cit., pp. 317 y s.; C. CAMARDI, Tecniche di controllo dell'autonomia contrattuale nella prospettiva del diritto europeo, en Eur. dir. priv., 2008, p. 847; F. BOCCHINI y E. QUADRI, Diritto privato, 3. ${ }^{\text {a }}$ ed., Torino, 2008, p. 624; F. MACARIO, Dai «contratti delle imprese» al «terzo contratto»: nuove discipline e rielaborazione delle categorie, en Jus, 2009, pp. 311 y ss.; E. MiNERVINI, Il «terzo contratto», en Contratti, 2009, pp. 493 y ss.; R. FRANCO, Il terzo contratto: da ipotesi di studio a formula problematica. Profili ermeneutici e prospettive assiologiche, Padova, 2010, passim; M. TAMPONI, Liberalizzazioni, «terzo contratto» e tecnica legislativa, en Contr. impr., 2013, pp. 91 y ss.

14 Tales adaptaciones y modificaciones continuas son la clara señal de cómo el legislador siente la necesidad de adaptar la normativa de consumo a la siempre variable exigencia de tutela que el mercado genera. En particular, en cuanto concierne a la modificación más reciente, el d.lg. 2 agosto 2007, n. 146, con el cual ha sido modificada la disciplina de la práctica comercial de la publicidad y otras comunicaciones públicas; el d.lg. 23 ottobre 2007 , n. 221, con el cual ha sido introducida una especial disciplina para la comercialización a distancia de servicios financiera a los consumidores; la 1. 24 diciembre 2007, n. 224 , modificada posteriormente por la 1.23 julio 2009, n. 99, con la cual se vio modificada la disciplina de la acción colectiva introduciendo la c.d. acción de clase; el d.lg. 13 agosto 2010, n. 141 con el cual ha sido modificada la disciplina del crédito al consumo; el d.lg. 25 mayo 2011, n. 79 con el cual ha sido modificada la normativa relativa a los contratos de multipropiedad y de venta de viajes combinados (hoy contenidos en el código de turismo); el d.l. 24 de enero 2012, n. 1, con el cual ha sido introducido el artículo 37 bis cod. cons. relativo a la tutela administrativa sobre las cláusulas abusivas; y, por último, el d.lg. 21 fe- 
en el que se individualizan las principales disposiciones sobre la tutela del consumidor, definido como «toda persona física que actúe con fines ajenos a su actividad comercial, industrial, artesanal o personal» ${ }^{15}$.

La relevancia bajo el prisma constitucional de la posición del consumidor $-\mathrm{y}$ del contratante más débil, en general - emerge, aunque en ocasiones de manera impropia, desde los primeros artículos del código de consumo que, en su artículo 2 c. cons., anuncia los derechos fundamentales de los consumidores ${ }^{16}$. El precepto mencionado ha sido objeto de atención por parte de la doctrina que, aun apreciando la inclusión de derechos que se refieren al consumidor, ha evidenciado su imprecisa formulación ${ }^{17}$.

En el seno de tal precepto quedan determinados individualmente cuáles son los derechos fundamentales del consumidor que, bajo el paraguas de la Carta constitucional, vienen reconocidos a cualquier persona ${ }^{18}$. Un

brero 2014, n. 21 que modifica la disciplina relativa a los contratos a distancia y a los contratos negociados fuera de los establecimientos mercantiles. Sobre el tema, G. D'AMICO, $L a$ riforma del codice del consumo, Padova, 2015, pássim.

${ }^{15}$ Sobre la problemática de la individualización de la noción de consumidor v. ya E. Minervini, Tutela del consumatore e clausole vessatorie, Napoli, 2001, pp. 42 y ss. y, más recientemente, F. MAZZASETTE, La nozione di consumatore: una questione ancora aperta, en G. Cavazzoni, L. Di Nella, L. Mezzasoma y V. Rizzo (a cura di), Il diritto dei consumi: realtà e prospettive, Napoli, 2008, pp. 83 y ss.; L. MezZAsoma, La protección del consumidor y del usuario en el ordinamiento italiano (la noción de consumidor y usuario), en Revista Práctica Derecho de daños, La Ley, n. ${ }^{\circ}$ 116/2013, septiembre-octubre 2013, pp. 8 y ss. y, da ult., ID., Il consumatore e il professionista, cit., pp. 13 y ss.

${ }^{16} \mathrm{G}$. ALPA, I diritti dei consumatori e il «Codice del consumo» nell'esperienza italiana, en Contr. impr./Eur., 2006, pp. 18 y ss.; G. VetTORI, Artículo 2, en E. CAPOBIANCO y G. PERLINGIERI (a cura di), Codice del consumo annotato con la dottrina e la giurisprudenza, Napoli, 2009, p. 11; G. ChInE, Artículo 2, en V. CuFfaro (a cura di), Codice del consumo, 3. ${ }^{\text {a }}$ ed., Milano, 2012, pp. 13 y s. Estas disposiciones representan la trasposición en el seno del código de consumo del artículo 1 de la 1.30 luglio 1998, n. 281 que había introducido por primera vez el elenco de situaciones que garantizan la protección del contratante más débil. Sobre este punto, v., R. ColaGRande, Disciplina dei diritti dei consumatori e degli utenti, en Nuove leggi civ. comm., 1998, pp. 700 y ss.; E. MinerVINI, I contratti dei consumatori e la legge 30 luglio 1998, n. 281, en Contratti, 1999, pp. 938 y ss.; G. AlPa, Artículo 1, in G. AlPa y V. LeVI (a cura di), I diritti dei consumatori e degli utenti, Milano, 2001, pp. 4 y ss.; ID., La codificazione del diritto dei consumatori. Aspetti di diritto comparato, en Nuova giur. civ. comm., 2009, p. 244; S. BENUCCI, La disciplina dei diritti dei consumatori e degli utenti, en G. VetToRI (a cura di), Squilibrio e usura nei contratti, Padova, 2002, pp. 162 y ss.; V. Cuffaro, La tutela dei diritti, en N. LIPARI (a cura di), Trattato di diritto privato europeo, IV, Padova, 2003, p. 701.

17 Para cualquier referencia sobre este punto, v. G. BerTI DE MARINIS, Disciplina del mercato e tutela dell'utente nei servizi pubblici economici, Napoli, 2015, pp. 226 y ss.

${ }_{18}$ Sobre este punto, v. G. AlPa, La codificazione del diritto dei consumatori. Aspetti di diritto comparato, en Economia e diritto del terziario, 2009, p. 241. 
ejemplo, entre muchos, es el referente a los derechos de la salud que, enunciado en el artículo 2 c. cons., es expresamente reconocido en el artículo 32 cost. entre los derechos fundamentales de la persona. Precisamente por esta razón, el artículo 2 c. cons. ha sido criticado debido a su redundancia y, en algunos aspectos, por su superfluidad ${ }^{19}$. No debemos olvidar que el código de consumo es una Ley ordinaria que, en cuanto tal, no puede establecer $«$ Derechos fundamentales ${ }^{20}$, contextualmente debe ser reafirmado el alcance inmediatamente obligatorio de la norma constitucional que encuentra directa aplicación también en las relaciones entre particulares en ausencia de normas ordinarias que resulten de específica aplicación ${ }^{21}$.

Todo ello permite manifestar como, a pesar de la completa ausencia en el seno de la Constitución italiana de cualquier explícita referencia a la tutela del consumidor ${ }^{22}$, su relevancia puede inferirse - como tendremos ocasión de explicar a continuación - en vía interpretativa de las disposiciones constitucionales vigentes. De hecho, es especificado que la parte contratante más débil asume relevancia constitucional bajo un doble prisma: de un lado, el consumidor es una persona y, de otro, es un operador económico. Tal duplicidad hace que sean aplicables al mismo tanto las disposiciones constitucionales que tutelan la persona en cuanto tal, como aquellas que regulan las relaciones económicas ${ }^{23}$.

El hecho de que el consumidor sea, en primer lugar, una persona supone que el mismo gozará de todas las medidas de tutela constitucional que resultan expresión del principio personalista ${ }^{24}$. Tal valor fundamental

19 Para estas observaciones, v. P. PerlingIERI, Il diritto civile nella legalità costituzionale secondo il sistema italo-comunitario delle fonti, cit., pp. 513 y s.

${ }^{20}$ G. Alpa, Artículo 2, en G. Alpa y L. Rossi Carleo (a cura di), Codice del consumo. Commentario, cit., p. 31; D. Memmo, Artículo 2, en M. Franzoni (dirigido por), Codice ipertestuale del consumo, cit., Torino, 2008, p. 11; G. CHINÈ, Artículo 2, en V. Cuffaro (a cura di), Codice del consumo, pp. 12 y s.

${ }^{21}$ Sobre la necesidad de asegurar eficacia directa y preceptiva a las disposiciones constitucionales v. antes S. PUGLIATTI, La retribuzione sufficiente e le norme della costituzione, en Riv. giur. lav., 1949/50, I, p. 189. Esta perspectiva es posteriormente desarrollada por P. PERLINGIERI, Salvatore Pugliatti ed il «principio della massima attuazione della Costituzione», en Rass. dir. civ., 1996, pp. 807 y ss.; en ID., L'ordinamento vigente e i suoi valori, Napoli, 2006, pp. 295 y ss. y en ID., Interpretazione e legalità costituzionale. Antologia per una didattica progredita, Napoli, 2012, pp. 405 y ss.

${ }^{22}$ Sobre tal punto, L. Mezzasoma, La protección del contratante débil en la legislación italiana, en Rev. Jur. de Daños, 2012, 2, pp. 1 y ss.

${ }^{23}$ L. Mezzasoma, Consumatore e costituzione, cit., p. 314.

${ }^{24}$ En este sentido, M. Pennasilico, Metodo e valori nell'interpretazione dei contratti. Per un'ermeneutica contrattuale rinnovata, Napoli, 2011, p. 265, el cual admite 
es el núcleo del sistema constitucional italiano y, en busca de su expresión correcta en el artículo 2 const., que anuncia la exigencia de tutelar al ser humano en cualquiera de las manifestaciones de su personalidad ${ }^{25}$.

Las normas sectoriales que se ocupan de la parte contratante más débil, por tanto, además de encontrar su justificación constitucional en la necesidad de responder a las peculiares exigencias que se derivan de la persona-consumidor, encuentran un elemento constitucional ulterior y conexo en la necesidad de ver respetado el principio de igualdad sustancial previsto en el artículo 3, párrafo 2, const. Tal precepto impone, de hecho, a la República el «remover los obstáculos de orden económico y social, que, limitando de hecho la libertad e igualdad de los ciudadanos, impiden el pleno desarrollo de la persona humana» ${ }^{26}$.

El principio de igualdad, por tanto, no se limita a requerir un tratamiento no discriminatorio de los individuos, sino que impone al Estado intervenir a fin de que sean eliminadas aquellas situaciones de desequilibrio que caracterizan determinados sujetos respecto a otros. Respecto a este último sentido, es clara la conexión entre el artículo 3, párrafo 2, const. y la normativa sobre tutela de la parte contratante más débil. El consumidor es, de hecho, un sujeto que se encuentra en una situación de genética debilidad respecto a la propia contraparte contractual y, todo ello, puede calificarse como uno de aquellos «obstáculos de naturaleza económica y social» que «impiden el pleno desarrollo de la persona humana». La posición de poder en la cual se encuentra el profesional podría llevar a este último a abusar del mismo, determinando la necesidad de acciones que tienen la función de reequilibrar las relaciones de poder entre las partes imponiendo solo al profesional el cumplimiento de amplios y detallados deberes en favor del consumidor ${ }^{27}$.

Pero como se ha adelantado, la figura de la parte contratante más débil - aquella persona a tutelar-, asume específica relevancia consti-

expresamente la necesidad de reconocer a la ««persona-consumidor» la primacía de la cual la persona tout court ya goza sobre el plano de los valores y de los principios que informan el vigente ordenamiento italo-comunitario».

${ }^{25}$ Sobre el personalismo como valor fundamental de nuestro sistema jurídico v. ya P. PERLINGIERI, La personalità umana nell'ordinamento giuridico, Napoli, 1972, pp. 13 y s. y 163 y ss. e ID., Il diritto civile nella legalità costituzionale secondo il sistema italo-comunitario delle fonti, cit., p. 434.

${ }^{26}$ Sobre el artículo 3 Const. y sobre el principio de igualdad formal y sustancial vid. P. PERLINGIERI, o.u.c.,pp. 448 y ss. Donde se afirma la necesidad de interpretar los dos apartados del artículo 3 unitariamente, en función de la realización de la «igualdad en la justicia social».

${ }^{27}$ L. Mezzasoma, Consumatore e Costituzione, cit., p. 320. 
tucional también como operador del mercado. En este sentido, el consumidor es calificable como el último anillo de la cadena distributiva de productos y servicios o, dicho de otro modo, debería ser entendido como el sujeto que está en posición de condicionar la evolución del mercado a través de la propia elección de consumo. Para que esto ocurra en un modo ideal es, sin embargo, necesario que sea salvaguardada la efectividad y genuinidad de la elección contractual del contratante más débil en modo de sentar las bases para una adecuada disciplina del mercado. El hecho de tutelar al consumidor de forma tal que le garantice la posibilidad de efectuar elecciones reflexivas, además de garantizar una adecuada protección de la persona-consumidor, determina la posibilidad de obtener también - de una manera inmediata - una plena tutela del mercado. Las elecciones del consumidor, cuando sean plenamente ponderadas, permitirán premiar a los profesionales más ejemplares y sancionar aquellos que, por el contrario, no garantizan el suministro de bienes y la prestación de servicios de calidad.

No es casual que la gran parte de normativa de tutela del contratante más débil gire en torno a la exigencia de garantizar al consumidor que sea respetado el principio de transparencia, sea en la fase informativa, en la contractual, también al fin de permitir al contratante de concebir, de forma correcta, el contenido normativo y económico del contrato que va a celebrar con el profesional ${ }^{28}$.

Todo se pone claramente en línea con el concepto del mercado más moderno ${ }^{29}$. Esto, de hecho, a pesar de encontrar un reconocimiento constitucional en el artículo 41 const. que consagra la plena libertad de iniciativa económica siempre encuadrado, sin embargo, en la jerarquía de los valores recogidos en la propia Carta constitucional que subordina el perfil del «tener» a la cualidad del «ser» ${ }^{30}$.

${ }^{28}$ Sobre la indicencia del principio de transparencia en el contexto específico de la tutela del contratante más débil, V. RIzzo, Trasparenza e "contratti del consumatore (la novella al codice civile), Napoli, 1997, pp. 16 y ss.

${ }^{29}$ Según P. PERLINGIERI, La tutela del consumatore tra normative di settore $e$ codice del consumo, en G. CAVAzZoni, L. Di Nella, L. Mezzasoma y V. Rizzo (a cura di), Il diritto dei consumi: realtà e prospettive, cit., p. 19, por lo que, «por un lado, es bueno reconocer al mercado, es decir, a la producción y al consumo, un papel central en el sistema - cesando la actividad de las empresas, cesaría también la producción - , por otro lado, es necesario reiterar que todo lo referente a este contexto económico [...] tiene su propia ratio de naturaleza personalista y existencialista que tiende a privilegiar la ratio especulativa de las operaciones financieras».

${ }^{30} \mathrm{P}$. PERLINGIERI, Il diritto civile nella legalità costituzionale secondo il sistema italo-comunitario delle fonti, cit., pp. 165 y ss. 
El mercado, en este cuadro cultural, se convierte en uno de los instrumentos a través del cual el individuo puede realizar su propia personalidad asumiendo un carácter instrumental respecto al principio personalista ${ }^{31}$.

Los valores que regulan la iniciativa económica privada no son, por lo tanto, solo económicos sino que resultan ser en primer lugar existenciales $^{32}$. Prueba de eso, es localizable en el mismo texto constitucional que, si de un lado garantiza la libertad de iniciativa económica, del otro la somete al límite expreso de la utilidad social de modo que hacer evidente la situación subordinada de las actividades económicas con respecto del pleno e integral desarrollo personalidad de los individuos ${ }^{33}$.

Tales consideraciones, como se ha adelantado al principio, no pueden sino tener una fuerte incidencia justo sobre el plano de la correcta disciplina de la autonomía negocial que, desde siempre, actúa cual fundamento de la libertad de iniciativa económica privada, sigue esta evolución perdiendo los caracteres de intangibilidad que la caracterizaron resultando intensamente influenciada por los valores no patrimoniales que asumen una posición axiológica indudablemente más elevada con respecto de aquellos valores patrimoniales ${ }^{34}$.

Precisamente la influencia de tales principios y valores, además de justificar la proliferación de normas sectoriales sobre la tutela del contratante más débil, ha determinado un profundo replanteamiento de instituciones clásicas del derecho de contratos que vienen reinterpretadas para adaptar la disciplina contractual al cambio de forma de los valores y de intereses determinado por la nueva realidad económico-social ${ }^{35}$.

${ }^{31}$ Para una configuración del mercado como estatuto normativo vid. P. PERLINGIERI, o.u.c., pp. 477 y ss. En el mismo sentido, F. CRISCUOLO, Autonomia negoziale e autonomia contrattuale, en Trattato di diritto civile del Consiglio nazionale del notariato dirigido por P. Perlingieri, IV, 1, Napoli, 2008, p. 21.

32 Sobre este punto, vid. P. PerlingIERI, Mercato, solidarietà e diritti umani, en Rass. dir. civ., 1995, pp. 91 y ss.; ID., Conclusioni, en A. Bellelli, L. Mezzasoma y F. Rizzo (a cura di), Le clausole vessatorie a vent'anni dalla direttiva CEE 93/13, Napoli, 2013, pp. 175 y s.

${ }^{33}$ Cfr., P. Perlingieri y M. Marinaro, Artículo 41, en P. Perlingieri, Commento alla Costituzione italiana, 2. ${ }^{\mathrm{a}}$ ed., Napoli, 2001, pp. 284 y ss.

${ }^{34}$ De este modo P. Perlingieri, o.u.c., pp. 319 y ss. En perspectiva análoga F. CRISCUOlo, Autonomia negoziale e autonomia contrattuale, cit., pp. 186 y ss. y M. Pennasilico, Metodo e valori nell'interpretazione dei contratti, cit., pp. 153 y ss.

${ }_{35}$ Sobre la necesidad de subordinar los valores económicos a aquellos que tutelan la persona en cuanto tal, P. PERLINGIERI, La tutela del consumatore tra liberismo e solidarismo, in Riv. giur. Molise e Sannio, 1995, p. 97; ID., Il diritto privato europeo tra riduzionismo economico e dignità della persona, en Eur. dir. priv., 2010, pp. 345 y ss. 


\section{LA FORMA DEL CONTRATO EN EL CÓDIGO CIVIL Y EN LAS NORMAS DEL SECTOR: EL NEOFORMALISMO}

Uno de las instituciones que principalmente ha sufrido esta evolución es aquella relativa a la forma del contrato ${ }^{36}$. Tal vínculo, a pesar de ser claramente conocido y disciplinado por el Código Civil, ha padecido una profunda segunda lectura que solo puede ser comprendida a la luz de la evolución general que ha afectado el contrato y la propia autonomía negocial ${ }^{37}$.

El Código Civil italiano del '42, como digo, disciplina la forma del contrato calificándola en el artículo 1.325 , n. 4, c.c. como uno de los elementos esenciales del mismo. Del tenor del precepto, por tanto, se desprende que la carencia del elemento formal - al igual que la falta de acuerdo, del objeto y de la causa del contrato-, determinan la nulidad del mismo ${ }^{38}$.

A pesar de que - especifica el art. 1.325 , n. 4, c.c. - la forma es elemento esencial del contrato, solo cuando la falta de la misma se sanciona bajo la pena de nulidad es cuando se manifiesta aquello que en la doctrina clásica ha sido universalmente definido como principio de libertad de la forma de los negocios. Es decir, según el sentido de la norma, solo cuando existe un expreso pronunciamiento que imponga la exigencia de forma escrita ${ }^{39}$, se reconocerá como forma vinculante, mientras en el caso de que la ley deje libertad sobre el instrumento a través del cual efectuar la relativa manifestación de voluntad, debía dejarse a la libertad de las partes ${ }^{40}$. En este sentido, el principio

${ }^{36}$ La forma del contrato siempre ha estado caracterizada por una evolución instrumental con el fin de adaptarla a las variables exigencias del caso concreto. En este sentido, vid. A.M. SINISCALCHI, Solemnitates $e$ probationes all'alba della prima codificazione italiana, en Riv. dir. civ., 2005, I, pp. 378 y ss.

${ }^{37}$ Para cualquier referencia, G. BERTI DE MARINIS, La forma del contratto nel sistema di tutela del contraente debole, Napoli, 2013, pp. 9 y ss.

${ }^{38}$ U. BRECCIA, La forma, en V. RoPPO (a cura di), Trattato del contratto I, Milano, 2006, p. 498.

39 Sobre el hecho de que sea carga exclusiva del legislador determinar los supuestos en los que la forma escrita sea un requisito ad substantiam y sobre la marginal actuación del intérprete en este punto, vid. V. RoPPO, Il contratto, en Tratt. dir. priv. Iudica e Zatti, 2. ${ }^{\text {a ed., Milano, 2011, p. } 236 .}$

${ }^{40}$ En este sentido, la doctrina tradicional: G. STOLFI, Teoria del negozio giuridico, Padova, 1961, p. 162; G. OsTi, Contratto, en Noviss. Dig. it., IV, Torino, 1957, p. 509; A. DE CuPIs, Sul contestato principio di libertà delle forme, en Riv. dir. civ., 1986, II, p. 204; G. Cian, Forma solenne ed interpretazione del negozio, Padova, 1969, p. 16; C.M. BIANCA, Diritto civile, III, Milano, 2000, p. 273. 
de la libertad de forma venía a ser reconducido en el marco de la autonomía negocial como poder absoluto de los contratantes no solo para elegir si contratar, sino también con quién celebrar el contrato, qué contenido darle o decidir sobre la forma que adoptará el acto de autonomía negocial ${ }^{41}$.

En busca de concretar, siempre en el seno del tejido codificado, las normas que imponen requisitos formales, se debe hacer referencia al artículo 1.350 c.c. en el que se establece un largo elenco - si bien no exhaustivo- de los «actos que deben realizarse por escrito». Sin extenderme demasiado sobre el precepto, quisiera señalar que el objeto de los actos que se encuentran recogidos en la lista son todos aquellos contratos que tienen como objeto la transmisión, constitución o extinción de derechos reales sobre bienes inmuebles, así como algunos actos - por ejemplo, aquellos realizados en ultramar - que, a pesar de determinar el surgimiento de un derecho de disfrute y no de un derecho real, limitan de tal manera el goce del propietario sobre el bien que también se encuentran obligados a cumplir con el requisito formal ${ }^{42}$. Solo en esos casos, por tanto, el legislador ha querido sancionar la falta de forma del negocio con la nulidad del negocio ${ }^{43}$.

41 A. Genovese, Le forme volontarie nella teoria dei contratti, Padova, 1949, p. 17; G. STOLFI, Teoria del negozio giuridico, Padova, 1961, p. 181; A. LiSERRE, Formalismo negoziale e testamento, Milano, 1966, p. 31; M. GiongIANNI, Forma degli atti (dir.priv.), en Enc. dir., XVII, Milano, 1968, p. 1004.

${ }^{42}$ Sobre tales puntos, ampliamente, L. Bigliazzi Geri, U. Breccia, F.D. BusneLli y U. NAtoli, Diritto civile, Torino, 1986, p. 629; A. Liserre, Forma, en Il contratto in generale, XIII, en Tratt. dir. priv. Bessone, Torino, 1999, p. 402; A. BARENGHI, Artículo 1350, en Codice civile, dirigido por P. Rescigno, I, 7. a ed., Milano, 2008, pp. 2474 y ss.; R. Favale, Artículo 1350, en G. Perlingieri (a cura di), Codice civile annotato con la dottrina e la giurisprudenza, 3. a ed., Napoli, 2010, pp. 590 y ss.; S. Pagliantini, Artículo 1350, en E. Navarretta y A. Orestano (a cura di), Dei contratti in generale, II, en Comm. cod. civ. Utet, Torino, 2011, pp. 5 y ss.; F. ADDIs, Artículo 1350, en G. Bonilini, M. Confortini y G. Granelli (a cura di), Codice civile commentato, $4 .^{\text {a }}$ ed., Torino, 2012, pp. 3027 y ss.

${ }^{43}$ G.B. FerRI, Forma ed autonomia negoziale, en Quadrimestre, 1987, p. 322, afirma: «que el principio de libertad de forma está vigente en nuestro sistema, me parece que no debe ser puesto en duda. Sobre todo porque este principio representa una circunstancia estructural de la autonomía privada. En consonancia con la idea de autonomía privada es inherente la de libertad de escoger la forma, mediante la cual manifestar esta autonomía». Lo mismo se continúa comentando que en el artículo 1325, n. 4, c.c.: «el sistema general en el que tal norma se inserta necesariamente es (y no puede ser de otro modo) aquel en el cual, cuando no haya sido prevista legalmente una forma concreta, se cumple con el requisito formal (indispensable porque la regla negocial puede, en cualquier modo, manifestarse y ser, por tanto, objetivamente percepti- 
Es clara la ratio del precepto relativo a la forma en el código civil: la forma se entiende como el instrumento destinado a aquellas relaciones económicas que, poniéndonos en la óptica del legislador del 1942, se referían a los bienes de mayor relevancia económico-productiva. Situándonos por un momento en la estructura económica del 1942, de hecho, parece evidente como la propiedad sobre bienes inmuebles, la conservación de la misma, el disfrute de su rendimiento en conexión al derecho de propiedad, constituyen los elementos centrales de las relaciones económicas de la época. De ahí, la protección de la forma de los actos que tienen el poder de incidir sobre tales relaciones ${ }^{44}$. Un requisito formal que, en conjunto, tiene la equidistante función de conferir certeza al tráfico comercial que el ordenamiento consideraba de mayor relieve.

La súbita evolución del mercado, en cambio, ha hecho evidente como hoy esto se explica bajo un perfil tanto cualitativo como cuantitativo, a través de actos completamente distintos de las transacciones inmobiliarias. Relaciones de naturaleza financiera, bancaria, de consumidores, aseguradora y, en general, los actos relativos a la prestación de determinados servicios, representan el eje en torno al cual gira hoy la gran mayoría de los intercambios comerciales y, por ello, el movimiento de dinero más importante.

Actualmente, no puede decirse que, en el seno de estos sectores, se haya encontrado la proliferación de una gran masa de normas sectoriales estableciendo requisitos formales que cualificados, de manera extremadamente intensa, como requisitos neoformales ${ }^{45}$.

La cualificación de los mismos requisitos «neoformales» aprovecha de forma extremadamente intensa las particularidades que caracterizan tales nuevos límites de la autonomía negocial que, siempre con mayor

ble) con cualquier forma que el autor o los autores del negocio hayan elegido. Si esto no fuera así especificado en el propio n. 4 del artículo 1325 cod. civ., no tendría ningún sentido. Y todo esto, no es más que el principio de libertad de forma, el cual, como se ha dicho, se encuentra expresamente recogido en el artículo 1352 cod. civ.».

${ }^{44}$ Es inmediata la conexión con las exigencias de transcripción de los actos sometidos a dichos requisitos formales.

${ }^{45} \mathrm{G}$. CHINE, Il diritto comunitario dei contratti, en A. TIZZANo (a cura di), Il diritto privato dell'Unione europea, I, en Tratt. dir. priv. Bessone, XXVI, Torino, 2006, p. 796; E. Morelato, Nuovi requisiti di forma nel contratto, Padova, 2006, p. 1; U. Salvestroni, Spunti sul vecchio e nuovo formalismo, en Aa.Vv., Studi in onore di Giorgio Cian, II, Padova, 2010, pp. 2255 y ss.; E. FAZIO, Dalla forma alle forme. Struttura e funzione del neoformalismo negoziale, Milano, 2011, pp. 63 y ss.; R. DE RosA, L'analisi funzionale della forma, Milano, 2011, pp. 99 y ss.; F. ADDIS, «Neoformalismo» e tutela dell'imprenditore debole, en M. PENNASILICO (a cura di), Scritti in onore di Lelio Barbiera, Napoli, 2012, pp. 25 y ss. 
peso, presenta características diferentes, en parte, respecto a aquellas que comúnmente eran encontradas en los requisitos formales previstos en el código civil ${ }^{46}$. Tal refuerzo formalista que parece caracterizar nuestro ordenamiento ${ }^{47}$, se justifica por las nuevas funciones adoptadas de tales requisitos neoformales ${ }^{48}$.

Esta nueva tendencia, seguramente, no reconducible exclusivamente a normas comunitarias ${ }^{49}$, encuentra no obstante, su principal expre-

${ }^{46}$ Referencia sobre este punto en N. IRTI, Idola libertatis, Tre esercizi sul formalismo, Milano, 1985, pp. 28 y ss.; ID., Studi sul formalismo negoziale, Padova, 1997, pp. 79 y ss. Para cualquier consideración general sobre la renovada tendencia al formalismo, G. AlPA, La rinascita del formalismo. Aspetti di diritto contrattuale, en Riv. dir. civ., 1984, I, pp. 461 y ss.

${ }^{47}$ Una rigidez sustancialmente formalista ha sido apreciada por una parte de la doctrina Cfr. Tal rigidez formalista ha sido observada, entre otros, por V. RIzzo, Contratti del consumatore e diritto comune dei contratti, en R. FAVALE y B. MARUCCI (a cura di), Studi in onore di Vincenzo Ernesto Cantelmo, Napoli, 2003, pp. 620 y ss.; A. JANNARELLI, La disciplina dell'atto e dell'attività: $i$ contratti fra imprese e fra imprese e consumatori, en N. LIPARI (a cura di) Trattato di diritto privato europeo, III, Padova, 2003, pp. 48 y ss.; G. MARINO, La forma del contratto fra codice civile e normativa comunitaria (seconda parte), en Dir. form., 2003, p. 1775; S. PAGLIANTINI, La forma del contratto, appunti per una voce, en Studi senesi, CXVI, 2004, p. 116; F. DI GIOVANNI, La forma, en E. GABRIELLI (a cura di), I contratti in generale, II, en Trattato dei contratti dirigido por P. Rescigno e E. Gabrielli, Torino, 2006, pp. 767 y ss.; U. BRECCIA, La forma, en V. RopPo (a cura di), Trattato del contratto, I, Milano, 2006, pp. 535 y ss.; F. Venosta, Profili del neoformalismo negoziale: requisiti formali diversi dalla semplice scrittura, en Obbl. contr., 2008, pp. 872 y ss.; L. MoDICA, Vincoli di forma e disciplina del contratto. Dal negozio solenne al nuovo formalismo, Milano, 2008, pp. 119 y ss.; F. CRISCUOLO, Autonomia negoziale e autonomia contrattuale, en Tratt. dir. civ. CNN dirigido por P. Perlingieri, Napoli, 2008, pp. 221 y ss. y espec. pp. 231 y ss.

${ }^{48}$ La doctrina ha notado una evidente evolución del requisito de forma, sobre todo gracias a la función a la que está orientada a realizar: P. PERLINGIERI, La forma legale del licenziamento individuale come "garanzia», en Rass. dir. civ., 1986, pp. 1069 y ss.; V. Rizzo, Le «clausole abusive» nell'esperienza tedesca, francese, italiana e nella prospettiva comunitaria, Napoli, 1994, p. 538; R. AmAgLIANI, Profili della forma nella nuova legislazione sui contratti, Napoli, 1999, pp. 74 y ss.; D. VALENTINO, Obblighi di informazione, contenuto e forma negoziale, Napoli, 1999, pp. 243 y ss.; T. FEBBRAJO, L'informazione ingannevole nei contratti del consumatore, Napoli, 2006, pp. 65 y ss.; S. POLIDORI, Riflessioni in tema di forma dell'appalto privato, en Rass. dir. civ., 2007, pp. 702 y ss.; S. LANDINI, Formalità e procedimento contrattuale, Milano, 2008, pp. 113 y ss.; S. PAGLIANTINI, La forma nei principi acquis del diritto comunitario dei contratti: textform, forme di protezione e struttura del contratto, en G. DE CRISTOFARO (a cura di), I «princìpi» del diritto comunitario dei contratti, Torino, 2009, pp. 108 y ss.; L. ModicA, Formalismo negoziale e nullità: le aperture delle Corti di merito, en Contr. impr., 2011, pp. 16 y ss.

${ }^{49} \mathrm{Se}$ refleja, como ejemplo de la evolución sufrida, por una exigencia evidentemente protectora, el contrato de arrendamiento. Sobre ello, vid. M. BENINCASA, For- 
sión en la aplicación en nuestro ordenamiento de disposiciones provenientes de la Unión Europea que, con el fin de reglamentar el mercado de forma equilibrada, ha introducido requisitos de forma para determinados contratos. Tal ha sido el alcance de esa citada intervención y la proliferación de nuevos requisitos formales, a pesar de razones justificativas de gran valor, que desde otras instancias - si bien con argumentos y soluciones diversas - se ha llegado incluso a poner en duda la vigencia del principio de libertad de forma expuesta con anterioridad ${ }^{50}$.

Y no es casualidad que el ámbito principal, si bien no exclusivo, en el seno del cual se registra una base - tanto cuantitativa como cualitativa - bajo un perfil formal sea propiamente aquel relativo a las relaciones de consumidores, lato sensu ${ }^{51}$.

En el seno de este sector, se marcan claramente las diferencias sustanciales entre los requisitos formales del código civil y los requisitos neoformales. Mientras los primeros protegen exclusivamente la celebración del contrato y son caracterizados por la equidistancia y la finalidad reconducible solamente a la realización de la seguridad del tráfico; los requisitos neoformales, al contrario, protegen el procedimiento de formación del contrato por entero - desde la fase precontractual a la ejecutiva - , son caracterizados por la finalidad protectora de uno solo de los contratantes (el sujeto más débil) y sumando a la finalidad de garantizar la seguridad del tráfico jurídico, aquella mediante la cual crear relaciones negociales transparentes y equilibradas.

Se entiende, de hecho, que actualmente el requisito de forma puede cambiar sus propias funciones originales, dada su conversión en instru-

malismo e contratto di locazione, Milano, 2004, pp. 122 y ss.; M. FALABELLA, Locazione abitativa conclusa verbalmente e nullità dedotta dal locatore, en Giur. merito, 2009, pp. 653 y ss.; A. PIRAS, Locazione di immobili adibiti ad uso abitativo stipulata verbalmente e validità del contratto, en Riv. giur. sarda, 2009, pp. 144 y ss.; N. SCRIPELLITI, Locazione di fatto e nullità per violazione di forma scritta, en Arch. loc. cond., 2010 , pp. 630 y ss.; A.M. SINISCALCHI, La violazione dell'onere di forma nella locazione abitativa, en Obbl. contr., 2011, pp. 826 y ss.; M. TREPPAOLI, La nullità per difetto di forma di un contratto di locazione abitativa a scopo transitorio, en Riv. giur. sarda, 2011, pp. 132 y ss.

50 Para un análisis de las distintas posiciones doctrinales sobre este punto, vid. O. ProsPeri, Forme complementari ed atto recettizio, en Riv. dir. comm., 1976, pp. 189 y ss.; N. IRTI, Idola libertatis, Tre esercizi sul formalismo, cit., pp. 28 y ss.; ID., Studi sul formalismo negoziale, Padova, 1997, pp. 79 y ss.; B. GRASSO, La forma tra «regola» ed «eccezione» (a proposito di un libro recente), en Riv. dir. civ., 1986, pp. 49 y ss.; P. PERLINGIERI, Forma dei negozi e formalismo degli interpreti, Napoli, 1989, passim.

51 S. POLIDORI, Forme legali poste a tutela dei consumatori: funzioni e disciplina, en Rass.dir.civ., 2013, pp. 119 y ss. 
mento de protección valorable desde el punto de vista de los valores aportados. Si desde un lado es evidente como la previsión de requisitos formales no es por sí sola suficiente para reequilibrar las relaciones caracterizadas por su natural desequilibrio, es innegable que esta, unida a todas las disposiciones que tienden a regular el proceso formativo del contrato enriqueciéndolo de contenidos que, además de ser determinados previamente, deben también ser expresados de forma clara y trasparente, describe un articulado con valor de protección que garantiza al contratante más débil una oportuna protección contra el desequilibrio informativo. No obstante, no se descuida que es precisamente bajo el prisma informativo que se manifiesta de forma más evidente y penetrante la presencia de un desequilibrio en el seno de las relaciones de naturaleza de consumo. Es decir, el contratante más débil lo es precisamente porque le supone un gran esfuerzo hallar la información necesaria para formar plenamente su voluntad contractual. La forma, con su capacidad de ralentizar el tráfico comercial sujetándolo a contenidos trasparentes y verificables, seguramente juega un papel básico para vehicular correctamente la información necesaria con el fin de poner al alcance del contratante ¿desprotegido? la búsqueda de las características del contrato que va a celebrar.

\section{LA FORMA EN EL CONTRATO DE VENTA DE PAQUETES TURÍSTICOS}

Limitándome, por brevedad, al estudio de algunas de las relaciones con consumidores más significativas, parece evidente que las características descritas previamente se encuentran, con seguridad, en el seno de los contratos cuyo objeto es la venta de c.dd. viajes combinados. Tal figura negocial, centro de atención tanto del de legislación internacional ${ }^{52}$ como comunitario ${ }^{53}$, en su origen fue regulada en el código de consumo $^{54}$. Sucesivamente, no obstante, las particularidades que carac-

${ }^{52}$ En un primer momento, el contrato de venta de viajes combinados, fue regulado, bajo el perfil formal, por la Convención de Bruselas del 23 de abril de 1970, predispuesto por Unidroit y ratificada por el Ordenamiento italiano con la 1. 27 dicembre 1997, n. 1084.

${ }^{53}$ Se trata de la Direttiva 314/90/CEE incorporada en Italia con la 1. 17 marzo 1995, n. 11, la cual trata del perfil formal de estos contratos en el artículo 6.

${ }^{54} \mathrm{El}$ artículo 6 del d.lg. n. 111 del 1995, ha sido integralmente incorporado, en un primer momento, en el artículo $85 \mathrm{c}$. cons. Para un tratamiento general del motivo, consultar a S. BUSTI y A. SANTUARI (a cura di), Attività alberghiere e di trasporto nel 
terizan al sector, el legislador nacional ha decidido introducir todas las disposiciones en materia de turismo, comprendiendo obviamente la disciplina negocial del mismo, en el seno de un único texto normativo denominado código de turismo ${ }^{55}$.

Los requisitos formales impuestos para tal tipología de negocios, y que seguidamente serán analizadas, ven como función principal a cumplir aquella que garantiza la seguridad del tráfico, claridad y trasparencia del contenido negocial ${ }^{56}$. El contrato de venta de viajes combinados aparece, de hecho, como uno de los prototipos negociales dentro del conjunto de aquellos que verifican la evolución de los requistos formales en el actual sistema legislativo.

No es casualidad, en efecto, que el momento en el que emerge la incidencia de los requisitos formales en el seno de tales contratos sea

pacchetto turistico all inclusive: le forme di tutela del turista consumatore, Trento, 2006, pp. 191 y ss.; A. TuRCo, Il contratto di viaggio e il contratto di vendita di pacchetti turistici, en M. RiguZZI y A. ANTONINI (a cura di), Trasporti e turismo, en Tratt. dir. priv. eur. dirigido por A. Ajani y G.A. Benacchio, X, Torino, 2008, pp. 437 y ss. Desde el punto de vista del ordenamiento español y realizando un examen de la materia bajo el aspecto específico de la tutela del turista como consumidor, consultar J.A. TORRES LANA, M.N. Tur FAÚNDEZ y J.D. JANER TORRENS, La protecciòn del turista como consumidor, Valencia, 2003, pp. 15 y ss.

${ }^{55} \mathrm{El}$ «Código de la normativa estatal sobre la ordenación y el mercado del turismo» ha sido aprobado con el d.lg 23 maggio 2011, n. 79, y responde a la exigencia de dotar de autonomía el ámbito de la normativa concreta sobre consumo en función de las particularidades que distinguen al turista del consumidor. Para cualquier reflexión general sobre el código de turismo, vid. E.M. TRIPODI y G. CARDOSI, Il Codice del turismo. Guida alla nuova disciplina dopo il D.Lgs. n. 79/2011, Rimini, 2011, passim; V. CuFFARO, Un codice «consumato», en Corr. giur., 2011, pp. 1189 y ss.; S. CATERBI, La nuova normativa in tema di turismo, en Resp. civ. prev., 2011, pp. 2393 y ss.; M. COCUCCIO y M. LA TORRE, I contratti del turismo organizzato, en Corr. merito, 2011, pp. 1156 y ss.; E. MALAGOLI, Il nuovo codice del turismo: contenuti e garanzie, en Contr. impr./Eur., 2011, pp. 813 y ss.; N. SoldATI, Brevi note a margine del codice del turismo, en Contratti, 2011, pp. 815 y ss.; P. QUARTICELLI, Il contratto di vendita di pacchetto turistico nel nuovo Codice del turismo, en Contratti, 2012, pp. 205 y ss. En primer lugar ha de señalarse que, por razón de la entrada en vigor del mencionado código, ha sido expresamente derogada la 1. 27 dicembre 1977, n. 1084, con la cual se convertía ejectuva en Italia el Convenio Internacional sobre el contrato de viaje (CCV). Este Convenio Internacional venía considerado por la doctrina aplicable en cualquier caso, hasta el nacimiento del código de turismo, no obstante el nacimiento del d.lg. n. 111 del 1995 reflejado después en el código de turismo en aquello que no era regulado en el último texto, A. TAMBURRO, In tema di responsabilità del tour operator per l'attuazione degli obblighi di organizzazione e per l'esecuzione delle prestazioni complesse nel pacchetto turistico, en Dir.trasp., 2005, p. 1058; D. RICCIO, Gli obblighi di protezione del consumatore, ivi, 2006, p. 944.

${ }_{56}$ Cfr., las consideraciones de G. TASSONI, Il contratto di viaggio, Milano, 1998, p. 197; E. Morelato, Nuovi requisiti di forma nel contratto, cit., p. 70. 
propiamente, en contraposición a una visión «codificadora» del requisito formal, en concreto la relativa a los tratos preliminares ${ }^{57}$.

Un perfil de influencia formal en el ámbito precontractual, emerge con toda evidencia en la fase c.d. publicitario-informativa concretizadas en la regulación del llamado folleto informativo ${ }^{58}$. Tal instrumento, establecido en el artículo 38 código del turismo (en adelante c. tur.), representa la trasposición integral - con alguna modificación ${ }^{59}-$ del artículo 88 c. cons $^{60}$. Tal folleto, incluso representando un instrumento publicitario meramente discrecional - es decir, que no debe necesariamente ser predispuesto por parte del profesional-, además de tener un contenido vinculante con una finalidad evidentemente informativa ${ }^{61}$,

${ }^{57}$ M. Messina, «Libertà di forma» e nuove forme negoziali, Torino, 2004, p. 147; esta obra revela que la exigencia de transparencia común a todos los diversos requisitos de forma no afectan única y exclusivamente el requisito de forma escrita del contrato, sino que se refieren también a la fase precontractual que resulta constantemente caracterizada por nuevas cargas formales.

${ }^{58}$ Sobre ello, en general, E. GRAZIUSO, La vendita di pacchetti turistici. Aspetti sostanziali, processuali e risarcitori, Milano, 2013, pp. 78 y ss., insiste sobre la relevancia de tal instrumento como factor determinante para reconocer la tutela más amplia posible al turista consumidor. G. VILLANACCI, Il rapporto di consumo, en ID. (a cura di), Manuale di diritto del consumo, Napoli, 2006, pp. 278 y s.

${ }^{59}$ Se refleja, por las modificaciones que han influido en tales disposiciones respecto a la disciplina precedente, G. BERTI DE MARINIS, La tutela del turista consumatore nella disciplina contrattuale del codice del turismo, en Le Corti umbre, 2014, pp. 6 y ss.

${ }^{60}$ Sobre ello, vid. las consideraciones de F. Ricci, Artículo 88, in G. AlPa y L. Rossi CARleo (a cura di), Codice del consumo. Commentario, cit., pp. 584 y ss.; C. Alvisi, Artículo 88, en M. Franzoni (dirigido por), Codice ipertestuale del consumo, Torino, 2008, pp. 423 y ss.; F. Longobucco, Artículo 88, en E. CAPOBIANCO y G. PeRLINGIERI (a cura di), Codice del consumo annotato con la dottrina e con la giurisprudenza, Napoli, 2009, pp. 547 y ss.

${ }^{61}$ De este modo, por lo tanto, recita el artículo 38, apartado 1, c. tur.: «El folleto indica de forma clara y precisa: a) el destino, el medio, el tipo, la categoría del transporte utilizado; b) el alojamiento en hotel u otro tipo de establecimiento, la ubicación exacta con particular atención a la distancia respecto a las principales atracciones turísticas del lugar, la categoría o el nivel y las principales características con particular atención a los estándares de calidad ofertados, su aprobación y clasificación en el país en el que se encuentra; c) las comidas servidas; d) el itinerario; e) la información de carácter general aplicable al nacional de un Estado miembro de la Unión Europea en materia de pasaporte y visado con indicación de los términos para su obtención, así como las obligaciones sanitarias y las relativas formalidades para llevar a cabo el viaje y la estancia; f) el importe o el porcentaje del precio aportado como anticipo y los plazos para el cumplimiento del pago; g) la indicación del número mínimo de participantes eventualmente necesario para que el viaje sea realizado y de los términos que habrá de tener en cuenta para anular el viaje combinado; h) los términos, las modalida- 
viene claramente sujeto a un requisito de forma escrita. El hecho de que el legislador se refiere a un «folleto» hace evidente como en todos los casos en los cuales el profesional tenga la intención de publicitar los propios servicios turísticos, deberá hacerlo predisponiendo un documento escrito para entregar al turista consumidor en el que se contenga toda la información prevista en el artículo 38, parrafo 1, c. tur.. Parece ser que la citada norma intenta balancear dos exigencias diferentes: de un lado, encontramos la necesidad del profesional de hacerse conocer en el mercado y atraer a él el mayor número posible de clientes; del otro, se encuentra la del consumidor de no ser engañado por una información publicitaria que, al fin de resultar lo más alentadora posible, resulta no ser muy verdadera. Los requisitos de contenido previstos en la norma que refuerzan la necesaria predisposición por escrito de la mencionada información, dejan emerger la finalidad de protección de las disposiciones citadas para generar una publicidad informativa trasparente $^{62}$.

Incluso atendiendo a la fase propiamente informativa, no falta la previsión de contenido formal, como las anteriores, con una finalidad protectora. Y de hecho, el legislador del código de turismo, al disciplinar la información que debe ser ofrecida al turista-consumidor, prevé en el artículo 37, parrafo 1, que: «En el transcurso de los tratos y, en todo caso, antes de la celebración del contrato, el intermediario o el organizador proporcionarán por escrito información de carácter general concerniente a las condiciones aplicables a los ciudadanos de los Estados miembros de la Unión Europea en materia de pasaporte y visado con las indicaciones de los términos para su expedición, además de las obligaciones sanitarias y las relativas formalidades para efectuar el viaje y residencia». Tal disposición, que reproduce casi fielmente el precedente artículo 87 c. cons. ${ }^{63}$, representa el claro intento de la disci-

des, el sujeto en el que recae el ejercicio de derecho de revocación en el sentido de los artículos 64 a 67 del d. leg. 6 septiembre 2005, n. 206, en el caso de tratarse de un contrato negociado fuera de establecimiento mercantil o a distancia; i) los extremos de la cobertura del seguro obligatorio, de las eventuales pólizas de seguro voluntarias contratadas como cobertura de los gastos que se deriven para el turista por la anulación del contrato o por el retorno en caso de accidente o enfermedad, así como de las eventuales ulteriores pólizas de seguro suscritas por el turista.

${ }^{62}$ G. BERTI DE MARINIS, La tutela del turista consumatore nella disciplina contrattuale del codice del turismo, cit., pp. 8 y s.

${ }^{63}$ En general, sobre la disposición, v. F. LongobucCO, Artículo 87, en E. CAPOBIANCO y G. PERLINGIERI (a cura di), Codice del consumo annotato con la dottrina e con la giurisprudenza, cit., p. 543; F. ROMEO, Artículo 37, en G. DE CRISTOFARO y A. 
plina del sector por facilitar standards informativos de nivel elevado con el fin de salvaguardar una correcta y genuina formación en el consentimiento del consumidor ${ }^{64}$. Todo esto, no obstante, no solo en la fase precontractual sino también en el momento en que, según el segundo párrafo de la misma disposición, se refiere a la información que debe ser dada antes del inicio del viaje y, por consiguiente, no necesariamente antes de la celebración del contrato ${ }^{65}$. Ahora bien, en ambas circunstancias, el legislador se preocupa por vincular prestación de la mencionada información a un requisito de forma que requerirá al profesional para introducir los mencionados datos a disposición del consumidor en un soporte escrito.

Como se ha visto, si las relaciones formales se extienden con finalidad protectora también en la fase informativo-publicitaria, no puede ignorarse cómo las mismas características de protección son identificadas también en las nuevas previsiones formales relativas a la celebración del contrato. Los contratos de venta de viajes combinados, de hecho, no son ajenos a tal evolución que ha traído consigo, en general, la venta en el contrato de, no solo exclusivamente, un instrumento a través del cual crear relaciones negociales, sino también un medio a través del cual el profesional pueda facilitar la información al consumidor que carece de ella ${ }^{66}$.

ZacCARIa (a cura di), Commentario breve al diritto dei consumatori, Padova, 2010, p. 1445.

${ }^{64}$ En este sentido, C. Alvisi, Recesso e disdette turistiche, en Dir. tur., 2005, p. 213. En general, sobre la tendencia a imponer obligaciones de información precontractual en el seno de las contrataciones asimétricas, L. DI DonNA, Obblighi informativi precontrattuali. La tutela del consumatore, Milano, 2008, pp. 5 y ss. Sobre las funciones de estas cargas de información, cfr., F. GRECO, Informazione pre-contrattuale e rimedi nella disciplina della intermediazione finanziaria, Milano, 2010, pp. 2 y ss.

${ }^{65}$ Sobre la incidencia de los requisitos de información también en la fase ejecutiva del contrato, G. TASsoni, Artículo 37, en V. Cuffaro (a cura di), Codice del consumo, cit., pp. 881 y s. Al respecto, v. también, las consideraciones de C. AlvisI, Artículo 87, en M. FRANZONI (dirigido por), Codice ipertestuale del consumo, cit., p. 412 que, en relación a la información que debe ser aportada de forma previa a la salida, afirma: «las obligaciones de aportar una información reconocida en el segundo apartado de la citada disposición, encuentra su fuente en el contrato ya perfeccionado. La información suministrada genera, por ello, responsabilidad contractual del organizador o del vendedor, debiéndose entender esta obligación informativa como especificidad del contenido de la obligación de buena fe en la ejecución del contrato (ex art. 1375 c.c.) y la enumeración de la norma comentada como no taxativa.

${ }^{66}$ No es casual que, acompañando a las cargas formales, sean impuestos también estrictos requisitos de contenido. Cfr., M. MAGGIOLO, Il contratto predisposto, Padova, 1996, pp. 113 y ss.; G. VILlAnACCI, Il rapporto di consumo, en ID. (a cura di), Manua- 
En este contexto, la forma necesariamente escrita del contrato, cumple como instrumento a través del cual no solo se garantiza una sólida seguridad en el tráfico comercial, sino también una más correcta y trasparente forma de trasmitir el contenido informativo. Es prueba de ello el hecho de que la doctrina haya interpretado, en conexión directa con el artículo 36 c. tur., la imposición de fuertes restricciones contenidas en el artículo 35 c. tur. que, en cambio, prevé la necesaria formalización del mismo ${ }^{67}$. Este último precepto, que reproduce de forma casi integral lo dispuesto en el derogado artículo 87 c. cons ${ }^{68}{ }^{6}$, impone la redacción por escrito de estos contratos en términos «claros y precisos ${ }^{69}$ y prevé la obligación para el profesional de entregar una copia del contrato firmado por el profesional - no solo sellado como exponía la anterior normativa incluida en el código de consumo- al turista-consumidor ${ }^{70}$.

Nos encontramos, de este modo, ante un ejemplo práctico de la evolución del contrato que como mera expresión de la libertad de los contratantes, se convierte en instrumento en parte hetero rreglamentado destinado a producir cambios que, además de resultar económicamente ventajosos, son también equitativos ${ }^{71}$.

le di diritto del consumo, cit., p. 281; C. Alvisi, Artículo 86, en M. FrANZONI (dirigido por), Codice ipertestuale del consumo, cit., p. 399; F. Ricci, Artículo 86, en G. AlPA y L. Rossi CARleo (a cura di), Codice del consumo. Commentario, cit., pp. 578 y s.

${ }^{67}$ En este sentido, F. Ricci, Artículo 86, en G. AlPa y L. Rossi CARLeO (a cura di), Codice del consumo. Commentario, cit., p. 578; F. LongobucCO, Artículo 86, en E. CAPOBIanco y G. Perlingieri (a cura di), Codice del consumo annotato con la dottrina e con la giurisprudenza, cit., p. 535, donde remarca que «la norma analizada tiene una función complementaria con la precedente y tiende a establecer el c.d. contenido mínimo de garantía del contrato, que, por consiguiente, debe ser insertado en el documento redacto en forma escrita».

${ }^{68}$ S. CATERBI, La nuova normativa in tema di turismo, cit., p. 2404.

${ }^{69}$ Sobre el concepto de claridad y precisión aplicado a la específica temática de los viajes combinados, V. RopPo, I contratti del turismo organizzato, en V. Rizzo (a cura di), Diritto privato comunitario, Napoli, 1997, p. 309. Sobre transparencia como principio de carácter general, V. Rizzo, Trasparenza e "contratti del consumatore», cit., passim y, espec., pp. 24 y ss.

70 Esta modificación revela claramente la voluntad de reforzar el vínculo de naturaleza formal, P.M. PUTTI, Viaggi, vacanze e circuiti tutto compreso, en G. ALPA (a cura di), I diritti dei consumatori, II, en Tratt. dir. priv. eur. dirigido por A. Ajani y G.A. Benacchio, III, Torino, 2009, p. 497, en el cual, sin embargo, se manifiesta la naturaleza meramente informativa de la carga del requisito formal.

${ }^{71}$ Cfr., M.E. LA TORRE, Il contratto di viaggio «tutto compreso», en Giust. civ., 1996, II, pp. 32 y ss.; F. Longobucco, Artículo 86, en E. CAPobianco y G. PerlingieRI (a cura di), Codice del consumo annotato con la dottrina e con la giurisprudenza, cit., p. 535; C. Alvisi, Artículo 36, en M. FrANZONI (dirigido por), Codice ipertestuale del consumo, cit., p. 1441. 
Las principales dudas interpretativas relativas al precepto, que evidencia sin embargo un enfoque extremadamente rígido por una parte de la doctrina, se refieren a la correcta determinación de la naturaleza de citado requisito formal. De hecho, la escasa claridad de la norma hace que, frente a una parte de la doctrina que calificaba este requisito impuesto en el artículo 35 c. tur. como expresión de una norma imperativa que impone forma escrita ad substantiam ${ }^{72}$, exista la doctrina mayoritaria que, evidenciando que el legislador no sanciona con nulidad el incumplimiento formal, sostiene este requisito la finalidad meramente informativa y como tal, representaría un tertium genus $^{73}$ entre el requisito de forma ad substantiam y aquel previsto ad probationem $^{74}$.

La doctrina mayoritaria funda su posición, además de en el contenido literal según el cual la norma prescribe la «redacción» y no la «celebración» del contrato por escrito ${ }^{75}$, en el hecho de que la norma prevé exclusivamente que tal documento deba ser firmado (en la versión original de la disposición la firma era equiparada a la estampación de un sello ${ }^{76}$ por el profesional sin especificar la necesaria presencia también de firma del consumidor. Eso, evidentemente, llevaba a exigir un requisito formal fuera de los clásicos esquemas previstos en el ordenamiento

${ }^{72}$ En este sentido, E. Morelato, Nuovi requisiti di forma nel contratto, cit., p. 72. Esta posición parece ser avalada ambién por la jurisprudencia. Vid. Trib. Bari, 8 agosto 2000, en Dir. trasp., 2001, p. 783; Trib. Bari, 27 luglio 2005, en Dir. mar., 2006, p. 881. En sentido crítico respecto a esta imposición G. SILINGARDI, Forma ed elementi del contratto, en G. Sillngardi y F. MorAndi (a cura di), La «vendita di pacchetti turistici», Torino, 1998, pp. 43 y s.; L. PIERALlinI, I pacchetti turistici. Profili giuridici e contrattuali, Milano, 1998, pp. 24 y s.

${ }^{73}$ De este modo, G. Ciurnelli, Il contratto di viaggio, en G. ZudDas y G. CiurNELLI, Il contratto d'albergo. Il contratto di viaggio, Perugia, 1992, p. 92; S. MonTICELli, I contratti di viaggio, en G. CIURNELli, S. MONTICELli y G. ZudDAS, Il contratto d'albergo. Il contratto di viaggio. I contratti del tempo libero, Milano, 1994, pp. 165 y ss.; L. Pierallini, I pacchetti turistici. Profili giuridici e contrattuali, cit., p. 25; A. LEZZA, I contratti di viaggio, en N. LIPARI (a cura di), Diritto privato europeo, Padova, 1997, p. 875; C. Pollastri, Artículo 85, en Aa.Vv., Codice del consumo, Milano, 2006, pp. 665 y ss. A esta solución se llevaría valorando las similitudes con las previsiones formales ya previstas en el CCV.

${ }^{74}$ En este sentido, reconoce el requisito formal para los contratos de venta de viajes combinados, M.E. LA TORRE, I pacchetti turistici, profili giuridici e contrattuali, en Giust. civ., 1996, II, p. 35.

${ }^{75}$ Criticado por, A. Flamini, Viaggi organizzati e tutela del consumatore, Napoli, 1999, p. 88.

${ }_{76}$ Sobre esta originaria equiparación, ausencia en la actualidad de la norma vigente, v. E. Morelato, Nuovi requisiti di forma nel contratto, cit., p. 73. 
en función de los cuales, la previsión de la carga de forma escrita puede ser cumplido con la sola firma de todos los contratantes ${ }^{77}$.

A estas posiciones se suman aquellas que, a pesar de reconocer la imposibilidad de calificar el requisito formal en palabras que textualmente signifiquen la exigencia de una forma escrita ad substantiam, determinan el fundamento de este planteamiento en una interpretación del precepto orientada finalísticamente. Según esta reconstrucción, de hecho. La función del requisito formal es reconducida a razones meramente informativas a favor del turista-consumidor ${ }^{78} \mathrm{y}$, en cuanto tal, resultaría del todo desproporcionada la imposición de una sanción de nulidad de un contrato que carezca de la forma exigida ${ }^{79}$.

Sin embargo, los argumentos descritos no parecen convincentes ya que no se centran en la función real del requisito formal y, en esta situación, los avances en su protección, como parece más correcto, se manifestarán en consideración de la carga de la forma ad substantiam actus. En este sentido, a pesar de reiterar la función informativa del requisito mencionado, no puede perderse de vista como ello tiene la finalidad de garantizar una mayor certeza del tráfico jurídico y, en particular, un soporte duradero en el seno del cual el turista encuentra (y encontrará) una relación negocial cristalizada en el sentido de facilitar la verificación de la correcta ejecución de la prestación del profesional ${ }^{80}$. Siendo así, parece evidente la exigencia de reforzar el requisito formal calificándolo como elemento esencial del contrato, cuyo incumplimiento determinará su nulidad. En efecto, esta sanción que supone la desaparición de toda la relación negocial, estimula de forma decisiva al profesional a la correcta predisposición de la regulación negocial con el fin de garantizar el turista-consumidor un instrumento de información tras-

77 Sobre este punto, vid. L. Pierallini, I pacchetti turistici. Profili giuridici e contrattuali, cit., p. 25; N. PAOLUCCI, I servizi turistici, en F. CARIGELLA y G. DE MARzO (a cura di), I contratti dei consumatori, Torino, 2007, p. 512; D. RoMEO, L'acquisto di viaggi e vacanze «tutto compreso». I contratti per servizi turistici, en C. IURILLI y G. VECCHIO (a cura di), Il nuovo diritto dei consumatori, Torino, 2009, p. 215.

${ }^{78}$ F. Romeo, Artículo 35, en G. DE Cristofaro y A. ZacCaria (a cura di), Commentario breve al diritto dei consumatori, cit., p. 1440.

79 Cfr. G. CIURNELLI, Il contratto di organizzazione internazionale di viaggio, en Riv. giur. circol.trasp., 1989, p. 686; M. EROLI, L'informatica nel turismo, en P. CENDON (a cura di), Il diritto privato nella giurisprudenza, VIII, Torino, 2004, p. 362; L. Rossi Carleo, La vendita di pacchetti turistici, en L. Rossi Carleo y M. Dona, Il contratto di viaggio turistico, en Tratt. dir. civ. CNN, dirigido por P. Perlingieri, Napoli, 2010, pp. 67 y ss.; G. TAssoni, Artículo 35, en V. Cuffaro (a cura di), Codice del consumo, cit., p. 875.

${ }^{80}$ E. Morelato, Nuovi requisiti di forma nel contratto, cit., p. 73. 
parente y de control acerca de la correcta ejecución de las prestaciones que gravan su profesión ${ }^{81}$.

La jurisprudencia, seguramente con mayor firmeza que la doctrina, ha sido consciente de tales exigencias y particularidades y en las pocas ocasiones en las que se ha presentado la posibilidad de enfrentarse a la problemática, se ha decantado por sancionar con la nulidad el contrato de venta de viajes combinados en los que no se hubiera cumplido con la forma exigida. Esta solución ha sido adoptada, en algunas ocasiones, determinando la forma escrita como elemento esencial del citado contrato $^{82}$, y, en otras, considerando el artículo 35 c. tur. como norma imperativa que, siendo violada, será sancionada con la nulidad reconocida en el artículo 1.418 , párrafo 1, c.c..$^{83}$.

No se entiende que el objetivo aquí sea ocultar el hecho de que el cumplimiento de una sanción como la nulidad del contrato en el que falta el requisito formal pueda - por sí solo, aparentemente, como se verá más adelante- esconder intereses ocultos por el hecho de que la sanción de nulidad puede ser ejercitada por cualquiera. Esta característica, deducible del artículo 1.421 c.c., podría permitir un ejercicio abusivo del profesional que, después de haber dado vida a un contrato viciado, quiera liberarse del mismo con el fin de no tener que cumplir con los compromisos adquiridos ${ }^{84}$. No obstante, estas críticas pueden ser cómodamente superadas tomando consciencia de que el instituto de la nulidad, al igual que la forma del contrato, ha sido objeto de una reinterpretación actualizada que, realizada adecuadamente, permite dar una solución correcta para el caso concreto sin perjudicar la protección dada por la propia norma violada.

${ }^{81}$ S. POLIDORI, Riflessioni in tema di forma dell'appalto privato, en Rass. dir. civ., 2007, pp. 712 y s. Análogamente G. ColACINO, Le forme negoziali nel nuovo diritto dei contratti: le c.d.forme di protezione, en Studium iuris, 2010, p. 258.

82 Trib. Bari, 8 agosto 2000, en Dir. trasp., 2001, con nota critica di B. FIore, Pacchetti turistici: forma del contratto, danno da vacanza rovinata e limite risarcitorio, pp. 783 y ss.

83 Trib. Bari, 27 luglio 2005, en Dir. mar., 2006, p. 881.

${ }^{84}$ P. StAnZIONE y A. Musio, I contratti relativi alla fornitura di servizi turistici, en IDD. (a cura di), La tutela del consumatore, en Tratt. dir. priv. Bessone, Torino, 2009, p. 385; F. Romeo, Artículo 35, en G. DE CRISTOFAro y A. ZaCCARIa (a cura di), Commentario breve al diritto dei consumatori, cit.,pp. 1439 y s. El riesgo expuesto no parece, por otra parte, baladí ya que incluso la jurisprudencia ha reconocido al profesional la posibilidad de hacer valer la nulidad del contrato de viaje organizado por su falta de forma. De este modo, Trib. Treviso, 4 aprile 2003, en Dir. tur., 2004, p. 128. En sentido crítico sobre el enfretamiento jurisprudencial expuesto, S. POLIDORI, Riflessioni in tema di forma dell'appalto privato, cit., p. 713. 


\section{LA NULIDAD DEL CONTRATO EN EL CÓDIGO CIVIL Y EN LAS NORMAS DEL SECTOR: LA NULIDAD DE PROTECCIÓN}

Y, de hecho, adentrándonos en el análisis de la evolución experimentada por la institución de la nulidad contractual, resulta más frecuente que el legislador recurra al instrumento de la nulidad c. dd. relativa ${ }^{85}$.

Puesto que las normas de contenido sustancial se orientan, axiológicamente, a garantizar una tutela plena del contratante desfavorecido, es por ello por lo que sus disposiciones tienen un carácter sancionador ${ }^{86}$. Es decir, estas deben adaptar su propia estructura y disciplina a las concretas exigencias del supuesto que traten de regular, con el fin de poder realizar, incluso en un momento patológico, la finalidad que el ordenamiento tiende a perseguir ${ }^{87}$.

La nulidad c. dd. relativa ofrece un claro ejemplo de esta evolución en el sentido de que, sin tener en cuenta el esquema común del código civil diseñado para la nulidad contractual, prevé una limitación de los sujetos legitimados para ejercitar la acción, restringiéndolos solo a los contratantes protegidos según lo previsto en el artículo 36 , comma 3 , c. cons. ${ }^{88}$.

${ }^{85}$ Sobre ello vid., L. ModicA, Formalismo negoziale e nullità: le aperture delle Corti di merito, cit., pp. 16 y ss. En general sobre materia de nulidad de protección, M.P. MANTOVANI, Il sistema delle nullità di protezione e l'esercizio del potere giudiziale nel diritto dei consumatori, en Obbl. contr., 2010, pp. 444 y ss.; A. GENTILI, La «nullità di protezione», en Eur. dir. priv., 2011, pp. 77 y ss.

${ }^{86}$ Sobre el tránsito normativo que ha dado impulso en materia contractual a esta fase patológica de la relación negocial, vid. L. FERRONI, La moderna concezione costituzionale e comunitaria di autonomia negoziale e la nuova filosofia cui si informa il regime delle invalidità, en ID., Saggi di diritto civile, Pesaro-Urbino, 2003, pp. 17 y ss.

${ }^{87}$ Sobre la necesidad de adecuar los remedios sancionadores a la finalidad perseguida por la norma violada, P. PerlingIeri, Nuovi profili del contratto, en Rass. dir. civ., 2000, pp. 568 y ss.; ID., La nullità del contratto fra esigenze protettive e principio di conservazione, en Ann. Fac. Econ. Benevento, 2003, n. 9, pp. 205 y ss.; ID., Il diritto civile nella legalità costituzionale, cit., p. 352, en el que afirma: «la disciplina de los contratos con consumidores, del contratante más débil, perturba la teoría clásica de la nulidad y refuerza la idea de que el orden concreto de intereses exige, también bajo el perfil patológico, una disciplina que se desprende no ya de la mera reconducción al tipo, sino de las particularidades del caso».

${ }^{88}$ La temática de la disciplina de la nulidad relativa es de gran interés y parece portadora de reflexiones sistemáticas primordiales. Basta, por ahora, la observación de cómo la temática de la restringida legitimación, con referencia específica al examen de oficio, ha sido objeto de numerosas reflexiones por la doctrina. Sobre este punto, vid. S. MontiCelli, Nullità, legittimazione relativa e rilevabilità d'ufficio, en R. FAVALE y 
La citada evolución se manifiesta de forma plena si prestamos atención a lo dispuesto en el artículo 1.421 c.c. ${ }^{89}$. En el precepto determina los sujetos legitimados para ejercitar la acción de nulidad como «cualquiera que tenga interés pudiendo ser relevado, de oficio, por el juez» a salvo, los casos en los que sean aplicables «diversas disposiciones legales» ${ }^{90}$.

Tras la regla general de legitimación absoluta, el propio legislador del ' 42 determina las posibles derogaciones que a él mismo le parece que deberían ser reguladas por una previsión expresa del legislador ${ }^{91}$.

El problema surge con la verificación de cuál sería la cobertura prevista para esta expresa derogación y, en particular, determinar la naturaleza excepcional de las disposiciones que prevén la detección de los casos de nulidad relativa. Esta posición se basaba en la circunstancia por la cual las disposiciones que preveían una limitación de la legitimación para ejercitar una acción de nulidad eran totalmente marginales, debiendo localizar la regla general en la legitimación absoluta ${ }^{92}$.

B. MARUCCI (a cura di), Studi in memoria di Vincenzo Ernesto Cantelmo, cit., pp. 259 y ss.; F. Venosta, Nuovi profili della nullità, en ID., Tre studi sul contratto, cit., pp. 211 y ss.; E. Minervini, Dei contratti del consumatore in generale, 2. ${ }^{\text {a }}$ ed., Torino, 2010, pp. 89 y ss.; I. PRISCO, Il rilievo d'ufficio della nullità tra certezza del diritto ed effettività della tutela, en Rass. dir.civ., 2010, pp. 1227 y ss.; R. SENIGAGLIA, Il problema del limite al potere del giudice di rilevare d'ufficio la nullità di protezione, en Eur. dir. priv., 2010, pp. 385 y ss. Posteriormente, ha sido debatida la cuestión de la convalidación o no de los vicios que determinan estas sanciones. Vid., por todos, S. Polidori, Nullità relativa e potere di convalida, en Rass. dir. civ., 2003, pp. 931 y ss.; S. MonTICELLI, La recuperabilità del contratto nullo, en Notariato, 2009, pp. 174 y ss. Para un atento análisis de los perfiles de la más estricta actualidad de la problemática, vid. G. PERLINGIERI, La convalida delle nullità di protezione e la sanatoria dei negozi giuridici, 2. ${ }^{\text {a }}$ ed., Napoli, 2011, pp. 35 y ss.; ID., La convalida delle nullità di protezione. Contributo allo studio della sanatoria del negozio nullo, en AA.Vv., Studi in onore di Giorgio Cian, II, cit., pp. 1901 y ss.; G. BILÒ, Rilevabilità d'ufficio e potere di convalida nelle nullità di protezione del consumatore, en Riv. trim., 2011, pp. 483 y ss.; I. PRISCO, Le nullità di protezione, Napoli, 2012, pp. 60 y ss.

${ }^{89}$ S. POLIDORI, Artículo 1421, en G. PERLINGIERI (a cura di), Codice civile annotato con la dottrina e la giurisprudenza, cit., pp. 1041 y ss.

${ }^{90}$ S. Polidori, Discipline della nullità e interessi protetti, Napoli, 2001, p. 77; F. DI Cıомmo, La rilevabilità d'ufficio delle nullità negoziale tra (artificiosi) limiti processuali ed incertezze giurisprudenziali, en Foro it., 2006, I, c. 2109 s.

${ }^{91}$ Cfr., S. POLIDORI, o.l.u.c.

${ }^{92}$ No faltaban, sin embargo, autores que reconstruyendo la ratio de las concretas disposiciones, encontraban indicios respecto a una determinación relativa también en relación a la nulidad para la cual el legislador no había especificado ninguna otra. En este sentido, D. BARBERo, Sistema del diritto privato italiano, Torino, II, 1965, p. 434, el cual analizando la ratio de la sanción de nulidad prevista por el legislador en el artí- 
Sin embargo, estos argumentos son merecedores de un nuevo análisis a la luz de la evolución experimentada por el ordenamiento que, cada vez con mayor frecuencia, determina hipótesis sobre las cuales la sanción de nulidad viene a ser puesta a total y exclusiva disposición del contratante protegido cerrando, de este modo, su legitimación para ejercitarse por parte del profesional. En este sentido, es suficiente resaltar el artículo 127, comma 2 del d.lg. n. 385 de 1993 (testo unico bancario) ${ }^{93}$; los artículos 23 , comma $3 ; 24$, comma 2 y 30 , comma 7 del d.lg. n. 58 de 1998 (testo unico finanziario) ${ }^{94}$; el artículo 2 del d.lg. n. 122 de 2005 (vendita di immobili da costruire) ${ }^{95}$, el artículo 36 , c. cons.$^{96}$ y el artículo 167 del d.lg. $\mathrm{n}^{\mathrm{o}} 209$ de 2005 (codice delle assicurazioni private) ${ }^{97}$.

culo 122, apartado 5, de la 1. 22 aprile 1941, n. 633, cuando el contrato de edición a término no indica el número mínimo de ejemplares a imprimir, encontrando en aquella norma una previsión detectada de tutela exclusiva del autor, tendía a limitar la legitimación para ejercitar la acción de nulidad solo a este.

${ }^{93}$ Se refleja sobre este punto G. CARRIERO, La trasparenza delle condizioni contrattuali nel Testo Unico: regole generali e controlli, en Dir. banca merc. fin., 1994, pp. 433 y ss. y, más genérico, G. CASTALDI, Il testo unico bancario: tra innovazione e continuità, Torino, 1997, pp. 45 y ss.; G. Molle y L. Desiderio, Manuale di diritto bancario e dell'intermediazione finanziaria, Milano, 2000, pp. 3 y ss.; U. MorERA, Contratti bancari (disciplina generale), en Banca borsa tit. cred., 2008, pp. 166 y ss.; G. Colacino, o.u.c.,pp. 255 y ss.

${ }^{94}$ Sobre este punto encontramos los comentarios a los concretos artículos contenidos en G. AlPa y F. CAPRIGLIONE (a cura di), Commentario al testo unico delle disposizioni in materia di intermediazione finanziaria, I, Padova, 1998, pp. 258 y ss.; A. BERTOLInI, Problemi di forma e sanzioni di nullità nella disciplina a tutela dell'investitore, cit., pp. 2344 y ss.; E. GUERINONI, Le controversie in tema di contratti di investimento: forma, informazione, ripensamento e operatore qualificato, en Corr. giur., 2011, pp. 36 y ss.; V. SANGIOVANNI, Mancata sottoscrizione e forma del contratto di intermediazione finanziaria, en Corr. merito, 2011, pp. 140 y ss.

95 Vid., para todo, L. MeZZASOMA, Il «consumatore» acquirente di immobili da costruire, cit., pp. 138 y ss.

${ }_{96}$ Para cualquier referencia sobre la disposición, vid. G. PASSAGNOLI, Artt. 36-38, en G. Vettori (a cura di), Codice del consumo, Commentario, cit., pp. 384 y ss.; E. Capobianco, Artículo 36, en E. Capobianco y G. Perlingieri (a cura di), Codice del consumo annotato con la dottrina e la giurisprudenza, cit., pp. 199 y ss.; C. PonGIBò, Artículo 36, en P. CENDON (a cura di), Commentario al codice civile, Codice del consumo, cit., pp. 433 y ss.; A. BARENGHI, Artículo 36, en V. Cuffaro (a cura di), Codice del consumo, cit., pp. 279 y ss.

97 E. Ferrante, Artículo 167, en M. BIN (a cura di), Commentario al codice delle assicurazioni, Padova, 2006, pp. 510 y ss.; M. СRocitTo, Commentario al codice delle assicurazioni private, Matelica, 2006, p. 239. Por último, sobre el punto, vid. A. REDI, La «Nullità di protezione» nel codice delle assicurazioni private, en G. CAVAZZONI, L. Di Nella, L. Mezzasoma y F. Rizzo (a cura di), La tutela del consumatore assicurato tra codice civile e legislazione speciale, cit., pp. 323 y ss. 
A esta proliferación de hipótesis que se encuadran en el seno de limitación expresa de los sujetos legitimados para ejercitar la acción de nulidad, va necesariamente unido el dato cualitativo consistente en la presencia de sanciones de invalidez caracterizadas por una clara finalidad protectora que, sin embargo, el legislador no las califica expresamente como nulidad relativa. Propiamente, por estas últimas hipótesis por las que resulta especialmente relevante determinar si la «relatividad» del ejercicio de la acción de nulidad puede ser aplicable también a los casos en los que no están expresamente previstos por el legislador. En el seno de tales hipótesis reaparece, no solamente el problema estudiado respecto a la nulidad del contrato de venta de viajes combinados por defecto de forma ${ }^{98}$, sino también - por mantenernos en el ámbito de los consumidores - la nulidad prevista por la falta de forma escrita en los contratos de multipropiedad (aprovechamiento por turnos ${ }^{99}$. Recientemente, la materia ha sido objeto de una importante intervención normativa desde la Unión Europea a través de la Directiva 2008/122/CE ${ }^{100}$ que, traspuesta por el d.lg. 23 de mayo 2011, n. 79, ha introducido una reforma completa de la citada materia que, a pesar de estar todavía contenida en el código de consumo, ha debido replantear su regulación ${ }^{101}$.

Sin tratar, por brevedad, las numerosas novedades introducidas, basta señalar que en la trasposición de la directiva comunitaria señala-

98 Vid. supra.

99 E. COSCETTI, La multiproprietà immobiliare, en Riv. giur. ed., 2010, pp. 799 y ss.; R. GALASSO, L'oggetto della multiproprietà e la disciplina del contratto, en Giur. it., 2011,pp. 61 y ss. Encontramos en la multipropiedad uno de los ejemplos que representan la evolución de derecho de propiedad y, consecuentemente, de las características que clásicamente lo distinguen, F. MARINELLI, Miti e riti della proprietà, en Rass. dir. civ., 2008, pp. 378 y ss. Posteriores ideas en este sentido en ID., Un'altra proprietà: l'enfiteusi, ivi, 2007, pp. 634 y ss.

100 Para cualquier reflexión acerca de la Directiva 2008/122/CE, v. L. SoldÀ, $L a$ multiproprietà, en G. GRASSELli (a cura di), La proprietà immobiliare, Padova, 2010, pp. 142 y ss.

${ }^{101}$ En particular, es señalado que en el artículo 2, la última normativa mencionada procede, previa derogación de la normativa anterior, a sustituir completamente el Título IV, Capítulo I, del código de consumo que aparece, también, respecto a la disposición de los artículos, completamente reformado. Vid. en general, R. PENNAZIO, Il disegno di legge comunitaria 2009, en Contr. impr./Eur., 2009, p. 1064. Sobre las novedades introducidas por la reforma mencionada en materia de multipropiedad, consultar G. TRAPANI, La nuova multiproprietà nel c.d. "Codice del turismo», en Contratti, 2011, pp. 941 y ss.; ID., La nuova multiproprietà, en Studi e materiali, 2011, pp. 1139 y ss.; C. SFORZA FogLIANI, Multiproprietà, locazioni ed altri temi immobiliari, en Arch. loc. cond., 2012, pp. 1 y ss. 
da, el legislador nacional ha reiterado la posición expresamente contenida en la norma previa por la que sanciona con la nulidad del contrato el incumplimiento de que el mismo sea celebrado bajo la forma escrita. Este requisito es establecido en el artículo 72 c. cons., que reproduce el derogado artículo $71 \mathrm{c}$. cons., imponiendo el requisito de forma escrita ad substantiam $^{102}$.

A pesar de lo expresamente previsto acerca de la sanción de nulidad, aparece evidenciada la persistencia del problema de determinar la norma aplicable a estas sanciones de invalidez. En efecto, ha sido señalado que el legislador no concreta si se trata o no de una nulidad relativa. Aunque basándonos en las consideraciones realizadas con anterioridad, la doctrina, casi unánimemente, sostiene que el legitimado para hacer valer la existencia de un vicio formal en el contrato sea el consumidor o el juez, aunque siempre en interés de aquel ${ }^{103}$.

Las razones sobre las que se basa esta oportuna posición, son identificadas en el análisis de aquellas que han de considerarse como las principales funciones para realizar la finalidad buscada por medio de la norma infringida. En este caso $-\mathrm{y}$ aplicando todo cuanto se ha afirmado respecto al contrato de viajes combinados - , el requisito de forma es exigido por razones de seguridad jurídica y trasparencia de su regulación y, todo ello, en cumplimiento de la exigencia de protección a la parte más débil ${ }^{104}$. Frente a estos datos, aparece totalmente coherente, a pesar del silencio de la ley, interpretar la misma sanción derivada de la

102 G. Franchi, Artículo 71, en Aa.Vv., Codice del consumo, cit., p. 631; G. CAPALdo, Artt. 70-72, en G. VetTori (a cura di), Codice del consumo, Commentario, cit., pp. 633 y s.; A. Turco, Artículo 71, en E. CAPOBIAnCo y G. Perlingieri (a cura di), Codice del consumo annotato con la dottrina e la giurisprudenza, cit., pp. 484 y s.; M. Costanza, Artículo 71, en P. CENDOn (a cura di), Commentario al codice civile, Codice del consumo, Milano, 2010, pp. 708 y s.; P.F. GiUgGioli, La multiproprietà, en F. DELFINI y F. MORANDI (a cura di), I contratti del turismo, dello sport e della cultura, en Trattato dei contratti, dirigido por P. Rescigno y E. Gabrielli, XIII, Torino, 2010, pp. 156 y s.; M. Ermini, Artículo 72, en V. Cuffaro (a cura di), Codice del consumo, cit., pp. 514 y ss.

${ }_{103}$ E. Gabrielli y A. Orestano, Contratti del consumatore, cit., p. 255; M. MesSINA, «Libertà di forma» e nuove forme negoziali, cit., p. 159; E. MoRElATO, Nuovi requisiti di forma nel contratto, cit., p. 165; A. FINESSI, Artículo 71, en G. DE CRISTOFARO y A. ZACCARIA (a cura di), Commentario breve al diritto dei consumatori, cit., p. 631 .

104 A. FINESSI, o.l.c., el cual anota que «en el timesharing la forma escrita ad substantiam se mezcla con la regla de transparencia que se traduce, en la fase de los tratos preliminares, en la obligación de aportar el documento informativo y, en sede de redacción del contrato, en la previsión de un contenido mínimo obligatorio, creándose de este modo una combinación de forma ad substantiam y forma ad informationem». 
falta de forma del contrato en el sentido de protección. Es decir, limitando la legitimación para invocar el vicio a la parte en la que se encuentra el sujeto protegido.

Como se indica, parece evidente que retener esta nulidad como invocable también para el profesional abriría, hipotéticamente, la puerta a posibles usos indebidos del instrumento invalidante que, diseñado a modo de tutela para el contratante más débil, podría acabar por comprometerlo.

No obstante, si la nulidad relativa podía ser considerada una sanción «excepcional» en el seno de un sistema que solo en contadas ocasiones utilizaba la limitación de los sujetos legitimados para ejercitar la acción, seguramente en la actualidad se puede registrar un crecimiento de las hipótesis de nulidad relativa. Además, a este dato se une la concienciación, desde el punto de vista de los valores, de la exigencia de proteger al contratante más débil también en una fase patológica de la relación negocial. Esta evolución no puede dejar indiferente al intérprete en el momento en que deba determinar la naturaleza excepcional o no de un determinado fenómeno jurídico ${ }^{105}$.

Siendo esto así, entonces, no debería existir el temor al hecho de extender la limitación de los sujetos legitimados para hacer valer la nulidad a los contratantes protegidos por la norma violada, de forma tal que garantice solamente a estos los beneficios derivados de la sanción invalidante. Una extensión de la nulidad relativa que fundada en una correcta interpretación hermenéutica destinada a privilegiar las relaciones materiales de los valores propios del ordenamiento evitaría que, detrás de interpretaciones formalistas, se pueden esconder resultados dañosos y poco convenientes ${ }^{106}$.

Si la ratio de la norma es la protección del contratante más débil a través del instrumento de la nulidad, la restricción de los sujetos legitimados para el ejercicio de la acción parece ser consecuencia directa de esta finalidad de tutela ${ }^{107}$.

${ }^{105}$ G. VetTori, Autonomia privata e contratto giusto, en Riv. dir. priv., 2000, p. 44.

106 Sobre el tema, v. P. PerlingIeri, Il diritto civile nella legalità costituzionale, cit., p. 374.

${ }^{107}$ S. Polidori, o.u.c., p. 106, según el cual «en el cambiado escenario que se presenta, las disposiciones que expresamente restringen a una sola de las partes el acceso a la acción de nulidad, pueden ser aplicadas por analogía, siempre que el legislador, imponiendo el remedio de tutela del contratante más débil (y por consiguiente, estabilizando la opción del ordenamiento sobre una ratio similar a aquella que ha inspirado las previsiones de nulidad relativa), no se haya pronunciado acerca de la 
Continuando con lo afirmado acerca de la interpretación de la citada norma, se presenta necesario preguntarse si la nulidad descrita en el artículo 1.421 c.c. se encuentra efectivamente distanciada respecto a lo previsto sobre nulidad relativa o si, por el contrario, es posible una reconstrucción unitaria de la invalidez negocial ${ }^{108}$.

Las posturas clásicas de la doctrina ${ }^{109}$ y de la jurisprudencia ${ }^{110}$, de hecho, han realizado una interpretación extremadamente extensa de lo dispuesto en el artículo 1421 c.c. describiendo los sujetos legitimados a hacer valer el vicio como «cualquiera que tenga interés». Y, en efecto, por una parte, se tendía a reconocer, en cada caso, plena legitimación a los contratantes debido a su propio interés en el hecho de haber celebrado un contrato nulo y, por otra, ante la posibilidad de considerar válida la legitimación de terceros, solicitaban únicamente la existencia de un simple interés en que el contrato sea declarado nulo ${ }^{111}$.

En la actualidad, esta interpretación ha sido sustituida por una que tenga en cuenta de manera más correcta el significado de la nulidad contractual. Es decir, teniendo en cuenta esta orientación que critica la amplia extensión de los sujetos legitimados bajo la interpretación del artículo 1.421 c.c., si bien, propiamente, la norma no sanciona un poder ilimitado por el que se pueda solicitar la nulidad del contrato, vincula tal oportunidad a la presencia de un interés que, lejos de poder ser confundido con la mera existencia de una ventaja por la parte recurrente,

legitimación de la acción. En esencia, la legitimación relativa, así como del resto, la parcialidad necesaria de la nulidad que afecta a una única cláusula contractual, se convierten en tratamiento de disciplina sobre la nulidad de protección, que no necesitaban de una expresa previsión textual, emergiendo simplemente de la ratio legis la necesidad de aplicar a aquellas tipologías de nulidad sobre el régimen jurídico que permite la óptima realización del interés». En ese sentido, G. PASSAGNOLI, Nullità speciali, Milano, 1995, p. 187.

108 A favor de esta solución, G. PerlingIERI, La convalida delle nullità di protezione e la sanatoria dei negozi giuridici, cit., p. 89.

109 F. PeCCENINI, Artículo 1421, en Della simulazione. Della nullità del contratto. Dell'annullabilità del contratto, en Comm. cod. civ. Scialoja-Branca, Bologna-Roma, 1998, p. 167; F. Di MARZIO, La nullità del contratto, cit., p. 997.

${ }_{110}$ Cass., 27 luglio 1994, n. 7017, en Rep. Foro it., 1994, voz Contratto in generale, p. 734, n. 437; Cass., 2 maggio 2007, n. 10121, en Società, 2008, p. 855.

${ }^{111}$ Es prueba de ello el hecho de que la jurisprudencia tienda a negar la presencia de legitimación de un tercero sólo donde actúa por el mero hecho de ver realizado el cumplimiento del precepto legal que sanciona con la nulidad del contrato. En este sentido, Cass., 17 marzo 1981, n. 1553, en Rep. Foro it., 1981, voz Contratto in generale, p. 634, n. 256; Cass., 12 luglio 1991, n. 7717, en Rep. Foro it., 1991, voz Contratto in generale, p. 675, n. 341; Cass., 11 gennaio 2001, n. 338, en Rep. Foro it., 2001, voz Contratto in generale, p. 795 , n. 456. 
debe, concretamente, determinarse en el hecho de que quien quiera ejercitar la acción debe hacerlo con un interés tal que merezca la tutela a la luz de nuestro ordenamiento ${ }^{112}$.

Como parece evidente, esta posición presenta la capacidad de reducir a unidad un fenómeno que, solo aparentemente, parece caracterizado por una división interna. De hecho, a esta reconstrucción ha de añadirse que es siempre responsabilidad del intérprete verificar si el sujeto que materialmente ejercita la acción es o no titular de un interés merecedor de tutela. En este sentido, por tanto, cualquier nulidad presenta perfiles de relatividad desde el momento en que el intérprete debe analizar la acción bajo un punto de vista axiológico (del legítimo interés) $)^{113}$.

Siendo así, aparece igualmente claro que habiendo calado este discurso en el ámbito que nos interesa, los casos legalmente previstos de nulidad relativa no son sino hipótesis en las cuales el mismo legislador ha efectuado un balance de valores con la intención de conseguir la exclusión del profesional como sujeto titular de intereses merecedores de tutela a través de la acción de nulidad ${ }^{114}$. El hecho de que este análisis haya sido realizado por el legislador en determinados y específicos supuestos, no excluye que el propio intérprete la deba hacer en todos los demás casos en los que el legislador ha guardado silencio.

Por tanto, esta interpretación basada en el dictado del código civil y corroborada por la elección del legislador de recurrir al instrumento de la nulidad relativa, permite considerar extensible la limitación de los sujetos legitimados a hacer valer el vicio a cualquier nulidad que presente una finalidad de protección de uno solo de los sujetos contratantes, de modo que limita al otro a valerse de los eventuales efectos favorables de la declaración de nulidad ${ }^{115}$.

Es relevante la plena conexión que resulta de este punto de vista analizado con aquel que subsana el vicio derivado la sanción por el ejercicio de la acción de nulidad. Bajo este punto de vista, el código civil es extremadamente claro reiterando que el contrato nulo, en contra de lo aplicable a los contratos anulables, no puede ser convalidado

112 S. Polidori, Discipline della nullità e interessi protetti, Napoli, 2001, pp. 123 y ss.

113 S. POLIDORI, Discipline della nullità e interessi protetti, cit., p. 128.

114 R. FAVALE, Nullità del contratto per difetto di forma e buona fede, cit., pp. 561 y ss.; ID., Forme per la validità del contratto e tutela dei contraenti, cit., pp. 973 y ss. Para cualquier otra consideración en este sentido, vid. D. Russo, Profili evolutivi della nullità contrattuale, Napoli, 2008, pp. 72 y ss.

${ }^{115}$ S. Pagliantini, L'azione di nullità tra legittimazione ed interesse, en Riv. trim., 2011, pp. 426 y ss. 
(art. 1.423 c.c.) pudiendo solamente ser convertido en otro contrato «que contenga los requisitos de sustancia y formal legalmente exigidos» (art. 1.424 c.c.).

La razón por la que el código civil opta por esta opción tan clara, debe ser concretada en el hecho de que la nulidad contemplada en el código civil era una sanción para la protección de intereses de naturaleza general que, por tanto, en modo alguno podía ser puesta a voluntad de una de las partes contratantes. Es decir, la idea subyacente es que la presencia de un contrato nulo en el ordenamiento jurídico provoca un daño al conjunto de la sociedad y, por ello, debía ser completamente retirado sin darle la posibilidad de encontrar acogida en el mismo.

¿De ahí? Siendo así, la prohibición de convalidación. Sin embargo, debemos preguntarnos si estos presupuestos subsisten efectivamente, también en las hipótesis en las que el legislador sanciona con la nulidad relativa un determinado contrato. De hecho, parece evidente que, en todas las circunstancias en las que se proceda - tanto legislativamente como por vía interpretativa - a limitar el círculo de legitimados solo a determinados sujetos, se reconoce que el interés tutelado por la invalidez del contrato no es general y perteneciente a toda la colectividad sino que, al contrario, se trata de interés del propio contratante. Por ello, la doctrina ha establecido las sustanciales diferencias entre la nulidad del código civil y la nulidad de protección que, si bien con alguna particularidad, parece reconocer la posibilidad de que, en determinadas circunstancias, pueden servir para subsanar el vicio de invalidez. Es decir, ocurre en todas las circunstancias en las que la protección basada en la invalidez del contrato sirve para tutelar intereses, no tanto supraindividuales como aquellos que recaen en la esfera del particular contratante $\mathrm{y}$, evidentemente, si el interés de la norma vulnerada ha sido realizado a pesar de la presencia del vicio ${ }^{116}$.

Profundizando en el tema objeto de estudio, reiteramos que lo afirmado hasta el momento sería así en los casos en los cuales existe un requisito de forma con finalidad de protección cuya violación, sin embargo, no haya causado una lesión efectiva del interés del consumidor a recibir de forma correcta, tempestiva y apropiada la información nece-

116 S. Monticelli, La recuperabilità del contratto nullo, en Notariato, 2009, 174 y ss.; G. PerlingIERI, La convalida delle nullità di protezione. Contributo allo studio della sanatoria del negozio nullo, en AA.Vv., Studi in onore di Giorgio Cian, II, Padova, 2010, 1901 y ss.; ID., Sanatoria e responsabilità del notaio ex artículo 28, l. 16 febbraio 1913, n. 89, en Le Corti umbre, 2013, 15 y ss.; S. BILò, Rilevabilità d'ufficio e potere di convalida nelle nullità di protezione del consumatore, en Riv. trim., 2011, 483 y ss. 
saria para la celebración del contrato. Según la doctrina, podrían concurrir estas circunstancias en lo que concierne a la forma prevista para el contrato de venta de viajes combinados y de multipropiedad (aprovechamiento por turnos) que hayan sido celebrados faltando la forma legalmente prevista, sin que de esta vulneración de la norma se deriven consecuencias negativas desde el punto de vista informativo ${ }^{117}$.

\section{CONCLUSIONES}

De todo lo afirmado se refleja que los principios del ordenamiento recogidos en la Constitución, delimitando un nuevo orden de valores, han adquirido la capacidad, no solo de influencia sobre el legislador para la creación de normas especiales que determinarán expresiones sectoriales respecto a los intereses jurídicamente tutelados, sino que también supondrán una nueva interpretación de las más clásicas instituciones del derecho de contratos que vienen actualmente reformuladas a la luz de los principios aplicables ${ }^{118}$.

Debe tenerse en cuenta que el desarrollo de esta evolución, en este punto concreto, ha venido marcado por numerosas intervenciones normativas por parte de los organismos comunitarios que parecen destinados a desarrollar en plazos razonables disposiciones que, al igual que la ya anunciada, confirman esta evolución.

Pensemos en la nueva Propuesta de Directiva del Parlamento europeo y del Consejo relativa a los viajes combinados y los servicios turísticos asistidos $[\mathrm{COM}(2013) 0512]^{119}$ que tiene como finalidad rediseñar

117 G. PerLINGIERI, La convalida delle nullità di protezione e la sanatoria dei negozi giuridici, cit., 59 s., según el cual, la convalidación del contrato relativamente nulo sería admisible cuando, «siendo violada la forma requerida o el proceso cronológicamente impuesto, esta violación (que ha supuesto la nulidad) no ha determinado para el contratante más débil perjuicios sustanciales o desventajas concretas (en tales casos los intereses finales, como por ejemplo el equilibrio contractual, podría resultar preservado). [...] Si hay constancia de un simple vicio estructural de nulidad que, como tal, no ha determinado necesariamente un desvalor de la regulación de los intereses, o no ha penetrado en el área de los valores. A tal grupo pertenecen, por ejemplo, las normas sobre forma de los contenidos en los artículos 117, apartado 3, t.u. banc.; 23, apartados 1 y 30 , apartado 7 , t.u. fin.; 71 c. cons., en materia de multipropiedad; 85 c. cons., en materia de venta de viajes combinados».

118 Vid. supra.

119 Esta Directiva está destinada a modificar el Reglamento (CE) n. ${ }^{\circ}$ 2006/2004 y la Directiva 2011/83/UE que deroga la Directiva 90/314/CEE del Consejo. Sobre esta directiva, V. RicciUTo, Le pratiche commerciali scorrette nella contrattazione a dis- 
integralmente la disciplina de los contratos de venta de viajes combinados adaptándola a la variable exigencias que caracterizan sectores tan dinámicos de nuestra economía. De hecho, la Propuesta de Directiva parece desarrollar, principalmente, una tutela específica y puntual del turista-consumidor con la intención de estimular el deseado equilibrio contractual en un sector que, evidentemente, es caracterizado por la presencia de desequilibrio entre las posiciones de los contratantes ${ }^{120}$.

Además, pensemos en la propuesta de Reglamento europeo de compraventa [COM(2011)613 def.] $]^{121}$ que nace con el objeto de dotar a todos los Estados miembros de una regulación uniforme en materia de transacciones transfronterizas para facilitar y estimular el tráfico comercial entre los ordenamientos jurídicos de cada Estado de la Unión ${ }^{122}$. La elección del instrumento regulador, teniendo en cuenta las particularidades del caso concreto ${ }^{123}$, parece ser el claro reflejo de la voluntad de imponer una disciplina uniforme e inmediatamente vinculante para cada Estado miembro, la cual se presenta como una clara expresión de

tanza, cit., pp. 1 y ss.; G. D'Amico (a cura di), La riforma del codice del consumo, Padova, 2015, passim.

${ }^{120}$ Sobre este punto, difusamente, R. SANTAGATA, La nuova disciplina dei contratti del turismo organizzato nel codice del turismo "dimidiato», en Nuove leggi civ. comm., 2012, pp. 1110 y ss. y ivi, para ulteriores referencias. Consultar, para cualquier referencia, G. BERTI DE MARINIS, La tutela del turista consumatore nella disciplina contrattuale del codice del turismo, cit., pp. 6 y ss.

${ }^{121}$ Sobre ello, en general, vid. G. D'Amico y M. BAsILE, al VII Congresso Giuridico-forense, tenutosi a Roma nei giorni 15-17 marzo 2012, publicado en Contratti, 2012, p. 7; C. CASTRONOvo, Sulla proposta di regolamento relativo a un diritto comune europeo della vendita, en Eur. dir. priv., 2012, p. 315; G. DE CRISTOFARO, Il (futuro) «diritto comune europeo» della vendita mobiliare: profili problematici della proposta di regolamento presentata dalla Commissione UE, en Contr. impr./Eur., 2012 , pp. 366 y ss; L. Mezzasoma, V. Rizzo y E. Llamas Pombo (dirs), La compravendita: realitá e prospettive, Napoli, 2015, pássim.

${ }^{122}$ G. Pongelli, La proposta di regolamento sulla vendita nel processo di creazione del diritto privato europeo, en Nuova giur. civ. comm., 2012, II, pp. 666 y ss.

${ }^{123}$ Se trata, por lo tanto, de un instrumento reglamentario de naturaleza opcional en el que, de un lado, la disciplina de la compraventa ahí contenida es inmodificable por parte de los Estados miembros, de otro lado, la concreta aplicación de la normativa se remite a la voluntad de los contratantes que, en el momento de la perfección del contrato, serán llamados a optar por la sujeción de su relación negocial a las disposiciones previstas en su regulación o rechazarlas. Sobre este punto, vid. A. Rocco, L'istituzione di uno strumento opzionale di diritto contrattuale europeo, en Contr. impr./ Eur., 2011, pp. 798 y ss.; J. BASEDOw, An Optional Instrument and the Disincentives to Opt in, en Contr. Impr./Eur., 2012, pp. 38 y ss. 
políticas armonizadoras del derecho europeo ${ }^{124}$. Este mecanismo, todavía en fase de aprobación, parece ser, además, manifestación de la exigencia de adaptar los actos negociales ciñéndose, principalmente, a los cambios que los valores subyacentes bajo el principio de autonomía negocial han de desarrollar. Se reserva gran atención a la fase precontractual centrada en la importancia dada al deber de información (arts. 23 y ss.) que recae sobre el profesional y el necesario control que ha de llevarse a cabo sobre el contenido de la reglamentación negocial, para sancionar todas las cláusulas que determinan el irracional desequilibrio entre las partes contratantes. Bajo este punto de vista, la propuesta de Reglamento de compraventa abre escenarios de gran interés desde el momento que, si bien con una disciplina diferente, prescribe la necesidad de efectuar una acusación de abusividad tanto para los contratos celebrados entre un profesional y un consumidor, como para los contratos celebrados entre profesionales ${ }^{125}$. Es decir, permite concluir que el hecho de limitar el ámbito de eficacia de las disposiciones relativas a la tutela de la parte más débil sea solo para el consumidor, supone el peligro de privar de protección a sujetos que, a pesar de ser profesionales, se encuentran en una posición de considerable debilidad respecto a la contraparte $^{126}$.

Esta atención prestada por el c.d. al profesional más débil, no es tampoco una novedad dentro del ordenamiento italiano que ha tenido la consideración de protegerlo en diversas figuras negociales que, a pesar de que sean solo aplicables entre sujetos necesariamente profesionales, permiten vislumbrar una situación de desequilibrio entre ellos. De este modo, por ejemplo, en las subcontrataciones reguladas en la 1.18 giugno 1998, n. 192 y en la cual se protege al subcontratante (empresario) como contratante más débil respecto al comitente (también empresario $)^{127}$. Este objeto de protección es perseguido a través de la aplicación

${ }^{124}$ M. Meli, Proposta di regolamento - Diritto comune europeo della vendita, en Nuove leggi civ. comm., 2012, p. 201.

125 Vid. artículos 79 y ss. de la Propuesta de Reglamento.

126 Sobre este punto de vista, difusamente, L. Mezzasoma, Il consumatore e il professionista, en G. Recinto, L. MEZzAsoma y S. CheRTi (a cura di), Diritti e tutele dei consumatori, cit., pp. 13 y ss.

${ }^{127} \mathrm{U}$. RuFFOLO, Il contratto di subfornitura nelle attività produttive. Le nuove regole della legge 18 giugno 1998, $n$. 192: «correzione» della autonomia contrattuale a tutela del subfornitore come professionista debole?, en Resp. comun. impr., 1998, p. 406; P.M. PUTTI, Contratto di subfornitura: forma e contenuto, en G. AlPA y A. ClarizIA (a cura di), La subfornitura, Commento alla legge 18 giugno 1998, n. 192, Milano, 1999, p. 78; G. GIOIA, I rapporti di subfornitura, en Giur. it., 1999, p. 671. 
a tales figuras negociales de los mismos instrumentos que, normalmente, son previstos para los consumidores. Por ejemplo, el requisito de forma escrita que impone a estos contratantes el artículo 2 de la 1.n. 192 del 1998, en claro cumplimiento de una función protectora ${ }^{128}$, deriva del hecho de que se incluyan, en este caso, las cargas de contenido en la celebración del contrato, con la finalidad de adaptarse al principio de transparencia ${ }^{129}$.

La misma consideración puede ser realizada en relación al contrato de franquicia regulado en la 1.6 maggio 2004, n. 129130. También en este caso el legislador ha sentido la necesidad de reequilibrar las posiciones de las partes contratantes, al igual que en los anteriores, entre sujetos que reúnen las características de empresarios teniendo presente que uno de ellos (el franchisee) se encuentra en una posición de evidente dependencia frente al franchisor ${ }^{131}$. No debe parecer extraño que, al igual que en lo dispuesto para las subcontrataciones, también aquí los instrumentos de protección se disciplinan en torno al requisito de forma escrita $^{132}$ unido a la previsión de un contenido que cumpla con los requisitos del contrato y la necesaria formulación de la cláusula de forma clara y trasparente respecto a la finalidad informativa ${ }^{133}$.

128 O. LOMBARDI, Forma legale e tecniche formative del contratto. La disciplina della subfornitura nelle attività produttive, Napoli, 2005, pp. $63 \mathrm{y} \mathrm{s.}$

${ }^{129}$ F. Delfini, Artículo 2, en AA.Vv., La subfornitura. Legge 18 giugno 1998, $n$. 192, Milano, 1998, p. 22; E. MinerVINI, Le regole di trasparenza nel contratto di subfornitura, en Giur. comm., 2000, I, p. 116.; D. MANTUCCI, Profili del contratto di subfornitura, Napoli, 2004, pp. 155 y s.; B. GRAZIANI, Contratto di subfornitura: forma e contenuto, en C. BERTI y B. GRAZIANI (a cura di), La disciplina della subfornitura nelle attività produttive, Milano, 2005, p. 52.

${ }_{130}$ Previamente, vid. R. BALDI, Il contratto di agenzia. La concessione di vendita, il franchising, Milano, 2001, p. 153; A. FRIGNANI, Il contratto di franchising, Milano, 1999, pp. 319 y ss. Puntualiza los riesgos que podrían derivar de una regulación del citado contrato, L. PETERs, Franchising: to legislate, or not to legislate, that is the question!, en Dir. comm. int., 1994, pp. 615 y ss.

${ }^{131}$ L. Delli Priscoli, Franchising e tutela dell'affiliato, Milano, 2000, p. 113; C. VACCÀ, Franchising: una disciplina in cerca di identità, en Contratti, 2004, p. 885.

132 Vínculo impuesto en el artículo 3, apartado 1 de la 1. n. 129 del 2004. Consultar, en este punto, F. BoRTOLOTTI, La nuova legge sul franchising, prime impressioni, en Contr. impr./Eur., 2004, p. 110; F. QuATTROCCHIO, Forma e contenuto del contratto, en O. CAGNASSO (a cura di), Norme per la disciplina dell'affiliazione commerciale, Torino, 2005, p. 98; G. DE Nova, La nuova legge sul franchising, en Contratti, 2004, p. 763; A. Frignani, Franchising. La nuova legge, Torino, 2004, p. 73.

133 V. PANDOLFINI, Gli obblighi informativi nella nuova legge sul franchising, en Contratti, 2005, pp. 73 y ss. 
En conclusión, parece evidente la fuerte incidencia que el cambio respecto a la aplicación de los valores que caracterizan a nuestro ordenamiento, ha tenido - y continúa teniendo - un pleno desarrollo no solo en las disciplinas del sector que imponen limitaciones a la autonomía negocial, sino también para orientar al operador del derecho en una interpretación correcta de las normas y de las instituciones que regulan el contrato. De hecho, ello no puede ser entendido como un mero instrumento a través del cual realizar intereses exclusivamente económicos. Por el contrario, si correctamente interpretado, el contrato se convierte en un medio a través del cual garantizar el tráfico comercial que no es solamente medio productor de riqueza, sino que entre sus características encontramos la capacidad de realizar valores como el equilibrio, igualdad, sensatez y balance que son máxima expresión de los valores contenidos en el seno de nuestra Constitución. No obstante, siendo sensibles a la realidad, estos principios no son solo propios del ordenamiento jurídico italiano sino que componen un complejo de valores compartidos por todos los Estados miembros que, en torno a ellos, deberían crear y estimular el nacimiento de un derecho privado común europeo. Solamente estimulando valores comunes europeos, parece posible la superación de todas las tendencias que quieren obstaculizar la creación de normas comunes y compartidas. Si, de un lado, parece evidente la imposibilidad de imponer normas uniformes de forma rígida y autoritaria, del otro, no se puede eximir de valorar a los puntos de contacto que, siendo concretamente cultivados, tienen la capacidad de crear un terreno fértil con la intención de que, con el paso del tiempo, se pueda llegar a alcanzar, de forma natural, la división de las disciplinas de todos los ámbitos privatistas. 
